\title{
The specific surface area and chemical composition of diamond dust near Barrow, Alaska
}

\author{
Florent Domine, ${ }^{1,2,3}$ Jean-Charles Gallet, ${ }^{1,2}$ Manuel Barret, ${ }^{1,2}$ Stéphan Houdier, ${ }^{1,2}$ \\ Didier Voisin, ${ }^{1,2}$ Thomas A. Douglas, ${ }^{4}$ Joel D. Blum, ${ }^{5}$ Harry J. Beine, ${ }^{6}$ Cort Anastasio, ${ }^{6}$ \\ and François-Marie Bréon ${ }^{7}$
}

Received 27 April 2011; revised 22 September 2011; accepted 3 October 2011; published 14 December 2011.

[1] Diamond dust (DD) refers to tiny ice crystals that form frequently in the Polar troposphere under clear sky conditions. They provide surfaces for chemical reactions and scatter light. We have measured the specific surface area (SSA) of DD at Barrow in March-April 2009. We have also measured its chemical composition in mineral and organic ions, dissolved organic carbon (DOC), aldehydes, $\mathrm{H}_{2} \mathrm{O}_{2}$, and the absorption spectra of water-soluble chromophores. Mercury concentrations were also measured in spring 2006, when conditions were similar. The SSA of DD ranges from 79.9 to $223 \mathrm{~m}^{2} \mathrm{~kg}^{-1}$. The calculated ice surface area in the atmosphere reaches $11000( \pm 70 \%) \mu \mathrm{m}^{2} \mathrm{~cm}^{-3}$, much higher than the aerosol surface area. However, the impact of DD on the downwelling and upwelling light fluxes in the UV and visible is negligible. The composition of DD is markedly different from that of snow on the surface. Its concentrations in mineral ions are much lower, and its overall composition is acidic. Its concentrations in aldehydes, DOC, $\mathrm{H}_{2} \mathrm{O}_{2}$ and mercury are much higher than in surface snows. Our interpretation is that DOC from the oceanic surface microlayer, coming from open leads in the ice off of Barrow, is taken up by DD. Active chemistry in the atmosphere takes place on DD crystal surfaces, explaining its high concentrations in aldehydes and mercury. After deposition, active photochemistry modifies DD composition, as seen from the modifications in its absorption spectra and aldehyde and $\mathrm{H}_{2} \mathrm{O}_{2}$ content. This probably leads to the emissions of reactive species to the atmosphere.

Citation: Domine, F., J.-C. Gallet, M. Barret, S. Houdier, D. Voisin, T. A. Douglas, J. D. Blum, H. J. Beine, C. Anastasio, and F.-M. Bréon (2011), The specific surface area and chemical composition of diamond dust near Barrow, Alaska, J. Geophys. Res., 116, D00R06, doi:10.1029/2011JD016162.

\section{Introduction}

[2] Small ice crystals in the atmosphere are frequently observed in the absence of clouds in polar and Alpine regions. These crystals precipitate slowly and are often referred to as clear sky precipitation, or diamond dust. In Polar Regions, these crystals often form in the boundary

\footnotetext{
${ }^{1}$ Laboratoire de Glaciologie et Géophysique de l'Environnement, CNRS-INSU, Saint-Martin d'Hères, France.

${ }^{2}$ Observatoire des Sciences de l'Univers de Grenoble, Université Joseph Fourier-Grenoble I, Grenoble, France.

${ }^{3}$ Takuvik Joint International Laboratory, Université Laval (Canada) and CNRS (France), Quebec, Quebec, Canada.

${ }^{4}$ U.S. Army Cold Regions Research and Engineering Laboratory, Fort Wainwright, Alaska, USA.

${ }^{5}$ Department of Earth and Environmental Sciences, University of Michigan, Ann Arbor, Michigan, USA.

${ }^{6}$ Department of Land, Air and Water Resources, University of California, Davis, California, USA.

${ }^{7}$ Laboratoire des Sciences du Climat et de l'Environnement, UMR CEA/CNRS/UVSQ, Gif-sur-Yvette, France.
}

Copyright 2011 by the American Geophysical Union. 0148-0227/11/2011JD016162 layer, where efficient radiative cooling of the snow surface can render the boundary layer air supersaturated with respect to ice. Vertical mixing within the boundary layer can also lead to the formation of diamond dust [Curry et al., 1996; van As and van den Broeke, 2006; Walden et al., 2003].

[3] Diamond dust (DD) may be important for physical and chemical processes during Polar winter. DD has long been suspected of having a strong radiative effect. For example, Girard and Blanchet [2001] calculated that the presence of DD increased downwelling IR radiation by up to $60 \mathrm{~W} \mathrm{~m}^{-2}$. DD may also decrease downwelling shortwave radiation. However, Intrieri and Shupe [2004], combined human observations with ground-based LIDAR and radar measurements and concluded the longwave radiative effect of DD was negligible and that the large effects previously attributed to DD were caused by overlying clouds that were difficult to detect by human observations in the polar night, when DD occurrences are most frequent.

[4] Other potentially important physical effects of DD include the reduction of visibility by DD [Meyer et al., 1991] and its impact on laser altimeters used to monitor the height of ice sheets [Walden et al., 2003]. The quantification of 
these physical effects requires the knowledge of DD physical properties and in particular of their specific surface area (SSA) and the mass of ice per air volume.

[5] DD likely also plays an important role in lower atmospheric chemical processes. First of all, precipitating DD provides a flux of water and trace constituents to the snowpack or ice surface. Second, DD provides ice surfaces that can catalyze heterogeneous reactions, such as those involved in ozone destruction and mercury oxidation, which lead to the frequently reported ozone and mercury depletion events (ODEs and MDEs) [Ariya et al., 2004; Bottenheim et al., 2009; Foster et al., 2001]. Diamond dust particles are 30 to $300 \mu \mathrm{m}$ long and can take up to $24 \mathrm{~h}$ to fall [Intrieri and Shupe, 2004; Ohtake et al., 1982]. Because of their small size, they have a large surface area to volume ratio and are present in the atmosphere longer than any other snow or ice crystal type. They therefore have ample time to provide a surface for heterogeneous chemical reactions to occur.

[6] Evaluating the catalytic effect of DD requires the knowledge of ice surface area per air volume, which can be obtained from its SSA and mass per air volume. At present, there are almost no data on the SSA of DD and little on its mass in the atmosphere. Without this information the potential impact of DD on atmospheric chemical reactions, photochemistry, remote sensing, and snow and ice albedo cannot be well modeled.

[7] Dominé et al. [2002] and Cabanes et al. [2002] observed four occurrences of extremely small precipitating ice crystals at Alert in the Canadian Arctic $\left(82.5^{\circ} \mathrm{N}\right)$. These crystals, which they identified as DD, had SSAs in the range 77 to $146 \mathrm{~m}^{2} \mathrm{~kg}^{-1}$. However, given the difficulties mentioned by Intrieri and Shupe [2004] to properly differentiate DD from actual snow (i.e., ice crystals falling from clouds), it now appears that these events may have been snow rather than DD. In fact, Cabanes et al. [2002] mention that during both events studied in February (complete darkness), clouds were probably present. For both April events studied, the presence of clouds is uncertain, but Cabanes et al. [2002] infer from vertical profiles of relative humidity $(\mathrm{RH})$ and temperature that the elevation of formation of the April DD was between 1500 and $2500 \mathrm{~m}$. This appears too high for DD, which mostly forms in the boundary layer, and although the crystals observed by Cabanes et al. [2002] had morphologies similar to positively identified DD crystals [Intrieri and Shupe, 2004; Lawson et al., 2006; Walden et al., 2003], we conclude that the crystals whose SSA were measured at Alert were probably not DD, but snow.

[8] Walden et al. [2003] performed a detailed study of atmospheric ice crystals at South Pole station, where they obtained photomicrographs of 20,000 ice crystals, a large number of them identified as DD. They did not actually measure SSA but their careful description of crystal shapes allowed them to obtain effective radii $r_{\text {eff }}$, from which SSA can be estimated by SSA $=3 /\left(\rho_{\text {ice }} r_{\text {eff }}\right)$ where $\rho_{\text {ice }}$ is the density of ice. Walden et al. [2003] indicate that their procedure to estimate $r_{\text {eff }}$ has been validated by Mahesh et al. [2001], but that due to crystal asymmetry, their $r_{\text {eff }}$ values could be overestimated by $15-50 \%$. In winter $r_{\text {eff }}=12 \mu \mathrm{m}$ so that SSA $=272 \mathrm{~m}^{2} \mathrm{~kg}^{-1}$, while in summer $r_{\text {eff }}=15 \mu \mathrm{m}$ so that SSA $=217 \mathrm{~m}^{2} \mathrm{~kg}^{-1}$. These values are higher than any snow SSA values measured [Domine et al., 2007], which stresses the potential importance of DD in physical and chemical processes. Such high SSA values for DD however need to be confirmed by actual measurements.

[9] Lawson et al. [2006] used ground-based cloud particle imagers at South Pole station to obtain the size, shape, number, and optical properties of atmospheric ice crystals. They obtained the size distribution and concentration of DD crystals in the atmosphere which roughly had a lognormal shape with a maximum around 3 crystals $\mathrm{L}^{-1} \mu \mathrm{m}^{-1}$, reached for a size (i.e., length of their largest dimension) of about $60 \mu \mathrm{m}$. The number concentration of DD crystals can be obtained from their data. However, their images were not as detailed as those of Walden et al. [2003] so it is difficult to derive SSA values.

[10] In Barrow, Alaska $\left(71^{\circ} \mathrm{N}\right)$, a site on the coast of the Arctic ocean, we collected DD on the ground and measured their SSA using the IR reflectance method of Gallet et al. [2009] during the Ocean-atmosphere-Sea ice-Snow (OASIS) campaign in March-April 2009. Dark nights and sunlit days alternated throughout our sample collection period. Sampling was facilitated by the presence of an outcropping melt-freeze crust over most of the snow surface, over which DD was easy to collect. It was also easy to evaluate the accumulation rate of $\mathrm{DD}$, so that the atmospheric particle concentration could be estimated after the settling velocity had been calculated. Some areas of the melt-freeze crust could be swept clean between DD precipitation events. Since the primary focus of the campaign was the chemistry of the Arctic boundary layer and snow close to the Arctic ocean, and since snow reactivity clearly depends on its chemical composition [Grannas et al., 2007], the DD was also analyzed for aldehydes, mineral and organic ions and some other organic constituents. To help quantify snow photochemistry, we also measured the optical absorption spectra of the water-soluble reactive chromophores (light absorbing species) contained in snow [Beine et al., 2011]. It is now well established that $\mathrm{H}_{2} \mathrm{O}_{2}$ and the nitrate ion $\mathrm{NO}_{3}^{-}$are important snow chromophores [Dominé and Shepson, 2002]. However, other unidentified chromophores are present, which probably represent the majority of the light-absorbing capacity of soluble species [Anastasio and Robles, 2007]. We therefore measured the snow optical absorption spectrum, measured $\mathrm{H}_{2} \mathrm{O}_{2}$ and $\mathrm{NO}_{3}^{-}$concentrations, and subtracted their spectra from those of the snow to quantify the absorption coefficient of those residual soluble chromophores. Last, mercury is an important atmospheric species but unfortunately, the mercury concentration of our DD samples was not analyzed during this campaign. However, we present $\mathrm{Hg}$ data from DD collected in Barrow at the same location from 12 March to 2 April 2006.

\section{Methods}

\subsection{Snow Sampling}

[11] In March and April, there was sufficient daylight to unambiguously identify DD crystals and detect clouds in the day time. The presence or absence of DD was checked several times during the day by visual inspection. No instrumental detection was used. DD was often observed during the campaign, and that was always when wind speed was very low, so it could not be mistaken with blowing snow.

[12] In 2009 DD was sampled about $300 \mathrm{~m}$ southeast of the Barrow Arctic Science Consortium's Barrow 
Arctic Research Center (BARC) building, around the point $\left(71^{\circ} 19.395^{\prime} \mathrm{N}, 156^{\circ} 39.685^{\prime} \mathrm{W}\right)$. This location is usually upwind of the Barrow area based on predominant wind direction (south-southeasterly), and there are no structures upwind of the sampling location. DD was usually sampled over the melt-freeze crust mentioned in the introduction. At times, and only for physical measurements, DD was also sampled on the roof of a nearby tent where the SSA measurements were undertaken. The thickness of the DD layer was measured with a ruler. Again, this was easily done because of the presence of the hard melt-freeze crust. The density of the diamond dust was determined by delimiting a $40 \times 40 \mathrm{~cm}$ square on the surface, collecting DD within it and weighing it. Knowing the thickness of the layer and the area over which it was sampled, its volume was determined, yielding its density. Areas of the melt-freeze crust were always kept clean by sweeping to allow collection of DD fallen over known time periods. When the daily DD accumulation was too low to measure its thickness, we waited a few days for a few $\mathrm{mm}$ to accumulate to obtain a density value.

[13] In 2006 DD sampling occurred in a similar location. Some of the results from this campaign were presented in an earlier paper [Johnson et al., 2008], but additional analyses are presented here. Surface samples were scraped from the upper $1 \mathrm{~cm}$ of the snow surface using a PTFE (Teflon) scoop. These samples represent recently blowing snow or stagnant surface snow. There was only one snow precipitation event (March 21) during the three week field campaign in 2006. DD samples were collected in Pyrex trays elevated on a rack $1.5 \mathrm{~m}$ above the snowpack surface with a PTFE (Teflon) scoop. Saltating snow grains rarely rise above $0.5 \mathrm{~m}$ during wind transport [Pomeroy and Gray, 1990], and therefore the samples collected from elevated glass trays represent DD precipitation and/or hoar frost.

\subsection{Specific Surface Area Measurements and Photomicrographs}

[14] The SSA of the 2009 samples was measured using the DUFISSS (DUal Frequency Integrating Sphere for Snow SSA measurements) instrument described by Gallet et al. [2009]. DD was transferred with a spatula into a cylindrical black sample holder $63 \mathrm{~mm}$ in diameter and $25 \mathrm{~mm}$ deep. The sample holder was then placed under the lower port of an integrating sphere $15 \mathrm{~cm}$ in diameter. The sample was illuminated with a $1310 \mathrm{~nm}$ or $1550 \mathrm{~nm}$ laser diode placed at the zenith and the reflected light was collected with an integrating sphere $15 \mathrm{~cm}$ in diameter. The signal was measured with an InGaAs photodiode. The signal was converted to reflectance using a set of six standards of reflectances between 4 and $99 \%$. The reflectance was converted to SSA using a calibration curve obtained with snow samples whose SSAs were measured using $\mathrm{CH}_{4}$ adsorption and whose reflectances were measured with DUFISSS [Gallet et al., 2009]. The accuracy of SSA measurements with DUFISSS is $10 \%$.

[15] Gallet et al. [2009] used two different wavelengths to measure snow SSA, depending on the SSA value. The actual variable to take into account is the optical depth, and a reliable measurement with DUFISS requires a sufficient sample optical depth so that the incident IR radiation will not reach the bottom of the sample holder where it would be absorbed, reducing the amount of reflected light and producing a negative artifact.

[16] Fresh snows of high SSA (which include DD) almost always have a very low density. The optical depth is proportional to SSA $\times \rho_{\text {snow }}$, where $\rho_{\text {snow }}$ is the snow density, and it was found [Gallet et al., 2009] that the high SSA of fresh snows did not compensate for their low densities, so that the penetration depth of the $1310 \mathrm{~nm}$ radiation was 2 to $3 \mathrm{~cm}$ or more, reaching the bottom. For light high-SSA snow, the $1550 \mathrm{~nm}$ radiation must be used. Ice is much more absorbent at $1550 \mathrm{~nm}$ than at $1310 \mathrm{~nm}$ [Warren and Brandt, 2008], so the penetration depth of light is about 20 times less at 1550 than at $1310 \mathrm{~nm}$. Using the $1550 \mathrm{~nm}$ wavelength therefore eliminates the negative artifact present at $1310 \mathrm{~nm}$, and the high SSA values guarantee a sufficiently high reflectance to have good signal and SSA accuracy.

[17] Here, we tested whether the $1310 \mathrm{~nm}$ radiation could also be used for high SSA-low density snow if the optical depth is artificially increased by compacting the snow. This was verified by measuring SSA simultaneously with 1310 and $1550 \mathrm{~nm}$, while progressively compacting the snow. It was found that moderate compaction (up to $\rho_{\text {snow }}=250 \mathrm{~kg} \mathrm{~m}^{-3}$ ) did not change the snow SSA. This will be detailed in a subsequent technical short note. We therefore used either the $1550 \mathrm{~nm}$ radiation without snow compaction, or the $1310 \mathrm{~nm}$ one with moderate compaction to measure the SSA of DD. Which wavelength to use was dictated only by convenience. If many DD samples had to be measured, $1550 \mathrm{~nm}$ was used. If only a few DD samples were to be studied within a series of regular snow samples, then the $1310 \mathrm{~nm}$ radiation was used for the whole series of measurements.

[18] To complement SSA measurements, photomicrographs of the DD crystals were taken using a reflex camera, extension tubes and a $35 \mathrm{~mm}$ lens that was inverted to increase the focusing distance. A fast flash (Nikon SB800) was used for lighting. Pictures were taken in reflected light over a black substrate. The magnification obtained with this setup is $\times 7$. The limiting factor in image resolution is the quality of the optics, as photographic lenses are not optimized to operate at such magnifications. It is therefore not useful to attempt to work at greater magnifications with a macro system.

\subsection{Chemical Measurements}

\subsubsection{Major Ions and Carbonaceous Species}

[19] Snow was collected around Barrow during the OASIS campaign to globally characterize its chemical composition and better understand carbon speciation in Arctic snow (D. Voisin et al., Carbonaceous species and HUmic LIke Substances (HULIS) in arctic snowpack during OASIS field campaign in Barrow, submitted to Journal of Geophysical Research, 2011; H. W. Jacobi et al., manuscript in preparation, 2011). Since we subsequently compare the compositions of DD to those of aged snows to differentiate sources of impurities, details on the overall snow analyses are given. A series $(\mathrm{n}=118)$ of samples was collected for dissolved organic carbon (DOC) and ionic composition measurements. These samples were kept frozen until analysis in Grenoble. DOC was measured by high temperature catalytic conversion to $\mathrm{CO}_{2}$ followed by Non Dispersive Infra Red spectroscopy on a Shimadzu VCSH instrument. Ions, including major ions $\left(\mathrm{Na}^{+}, \mathrm{NH}_{4}^{+}, \mathrm{K}^{+}, \mathrm{Mg}^{2+}, \mathrm{Ca}^{2+}, \mathrm{Cl}^{-}, \mathrm{NO}_{3}^{-}, \mathrm{SO}_{4}^{2-}, \mathrm{Br}^{-}\right)$and 


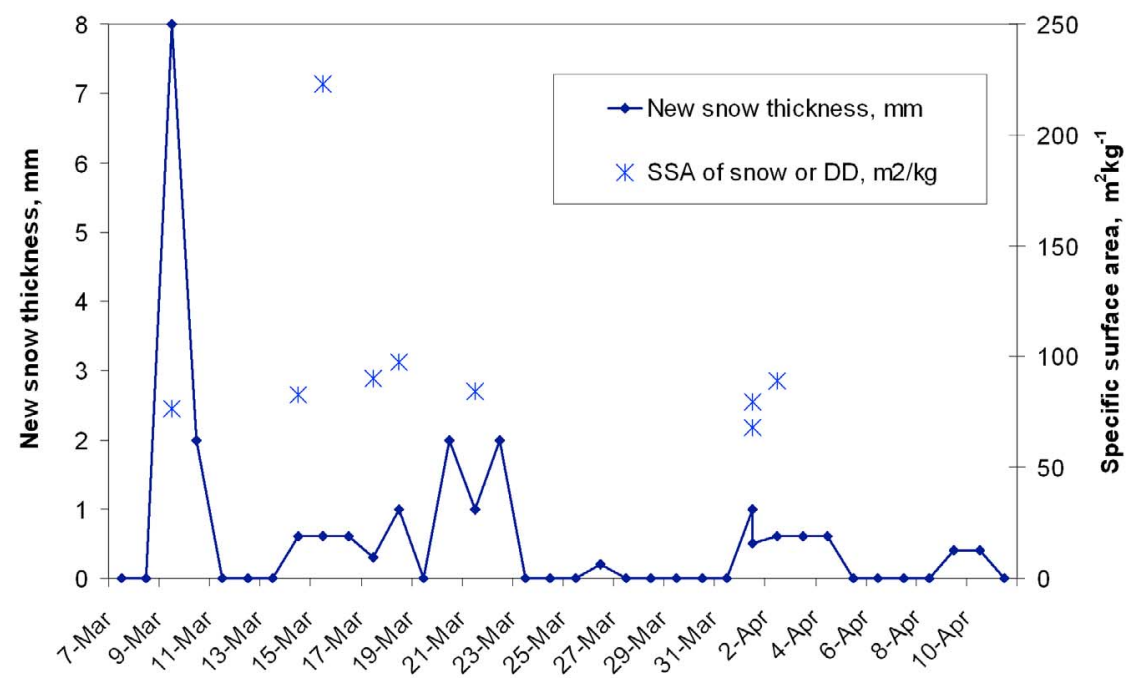

Figure 1. Time series of daily accumulation of precipitation. All precipitation is diamond dust, except on 9-10 March, where snow was observed. Small amounts of snow also fell with DD on 1st April. Measured SSA values are also shown.

some dicarboxylic acids (oxalic, glutaric, succinic) were measured by ion chromatography (IC). Among those samples, a fraction has been positively identified as DD $(n=7)$, possibly mixed with some surface hoar ( $\mathrm{SH}, 10$ to $40 \%$ in mass, by visual inspection). These samples were analyzed for ions and DOC.

\subsubsection{Aldehydes}

[20] Snow and DD samples were collected in $60 \mathrm{~mL}$ borosilicate glass vials for EPA analysis (Kimble Glass Inc., Vineland, NJ) with PTFE/silicone-lined caps. Vials were washed with ultrapure water and carefully rinsed before sampling. Vials were equilibrated to ambient temperature and then filled with samples. DD was collected directly into the vials by carefully scraping the surface so that the light and uncohesive layer of DD enters through the vial's neck. Snow samples were collected by directly inserting the vial into the layer of interest. After collection, samples were stored at $-40^{\circ} \mathrm{C}$ and thawed immediately prior to chemical analysis.

[21] Aldehyde concentrations were obtained by DNSAOA derivatization followed by HPLC separation and fluorescence detection. The analytical procedure essentially followed is that described by Houdier et al. [2000] with subsequent improvements detailed by Houdier et al. [2011]. The method measures both linear aldehydes and dicarbonyls at the trace level. The limit of detection (LOD) for reported aldehydes is in the $0.01-0.03$ ppbw range. We only report here data for formaldehyde (FA), acetaldehyde (Ac), glyoxal (GL) and methylglyoxal (MG), although traces of propionaldehyde and of other uncharacterized carbonyls were also detected.

\subsubsection{Mercury}

[22] Mercury concentrations were measured from the 2006 samples using a Nippon Instruments MA 2000 Atomic Absorption Spectrometer following the methods outlined by Johnson et al. [2008]. The Hg standard NIST SRM-3133 was analyzed to quantify the accuracy of a Nippon Instruments calibration standard. The limit of quantification of $1.0 \mathrm{ng} / \mathrm{L}$ is defined as $3 \mathrm{SD}$ of blanks run within analytical sessions. Replicate analyses of $100 \mathrm{ng} / \mathrm{L}$ standards yielded a $1 \mathrm{SD}$ analytical uncertainty of $\pm 2.5 \mathrm{ng} / \mathrm{L}$ while samples with concentrations less than $10 \mathrm{ng} / \mathrm{L}$ had a $1 \mathrm{SD}$ uncertainty of $\pm 1 \mathrm{ng} / \mathrm{L}$. Duplicate analyses were performed on more than half of the samples and yielded values within $10 \%$. Field replicates $(\mathrm{N}=21)$ yielded a mean relative standard deviation of $10 \%$. Procedural sample bottle blanks $(\mathrm{N}=3)$ averaged $1.2 \pm 0.5 \mathrm{ng} / \mathrm{L}$.

\subsubsection{Light Absorption of Soluble Chromophores}

[23] Over 500 surface snow samples were taken during the OASIS Barrow campaign between 27 February and 15 April 2009, and analyzed at the BARC. Our daily sampling efforts were coordinated with other OASIS snow sampling programs at Barrow (Voisin et al., submitted manuscript, 2011; F. Domine et al., Physical properties of the Arctic snowpack during OASIS, submitted to Journal of Geophysical Research, 2011; T. A. Douglas et al., Frost flowers in the Arctic ocean-atmosphere-sea ice-snow interface: 1. Chemical composition and formation history, submitted to Journal of Geophysical Research, 2011) whenever possible. The samples were stored at $-20^{\circ} \mathrm{C}$ for up to a couple of days if necessary. They were slowly melted and analyzed for their UV-vis optical absorption using a 100-cm Liquid Wave Core Cell (LWCC) and a TIDAS spectrometer in the range between 220 and $600 \mathrm{~nm}$. At $320 \mathrm{~nm}$ our $10-\sigma$ quantification level was on the order of $0.5 \times 10^{-3} \mathrm{~m}^{-1}$. Our measured values were well above the $10-\sigma$ quantification level in the range up to $500 \mathrm{~nm}$. Details of the sampling and analysis are described by Beine et al. [2011]. Prior to absorption analysis we took aliquots from each sample solution, froze them $\left(-20^{\circ} \mathrm{C}\right)$, stored them until the end of the Barrow campaign (4/15/09), and shipped them to our laboratory in Davis for analysis of $\mathrm{H}_{2} \mathrm{O}_{2}$ by HPLC and major anions by ion chromatography (IC) [Beine et al., 2011].

[24] For each sample light absorption spectrum we subtracted the contributions from $\mathrm{H}_{2} \mathrm{O}_{2}$ and $\mathrm{NO}_{3}^{-}$to determine the "residual absorption," $\alpha_{\lambda}$ (residual) at each wavelength that is due to light-absorbing species other than $\mathrm{H}_{2} \mathrm{O}_{2}$ or $\mathrm{NO}_{3}^{-}$. For a given sample we then summed the residual 


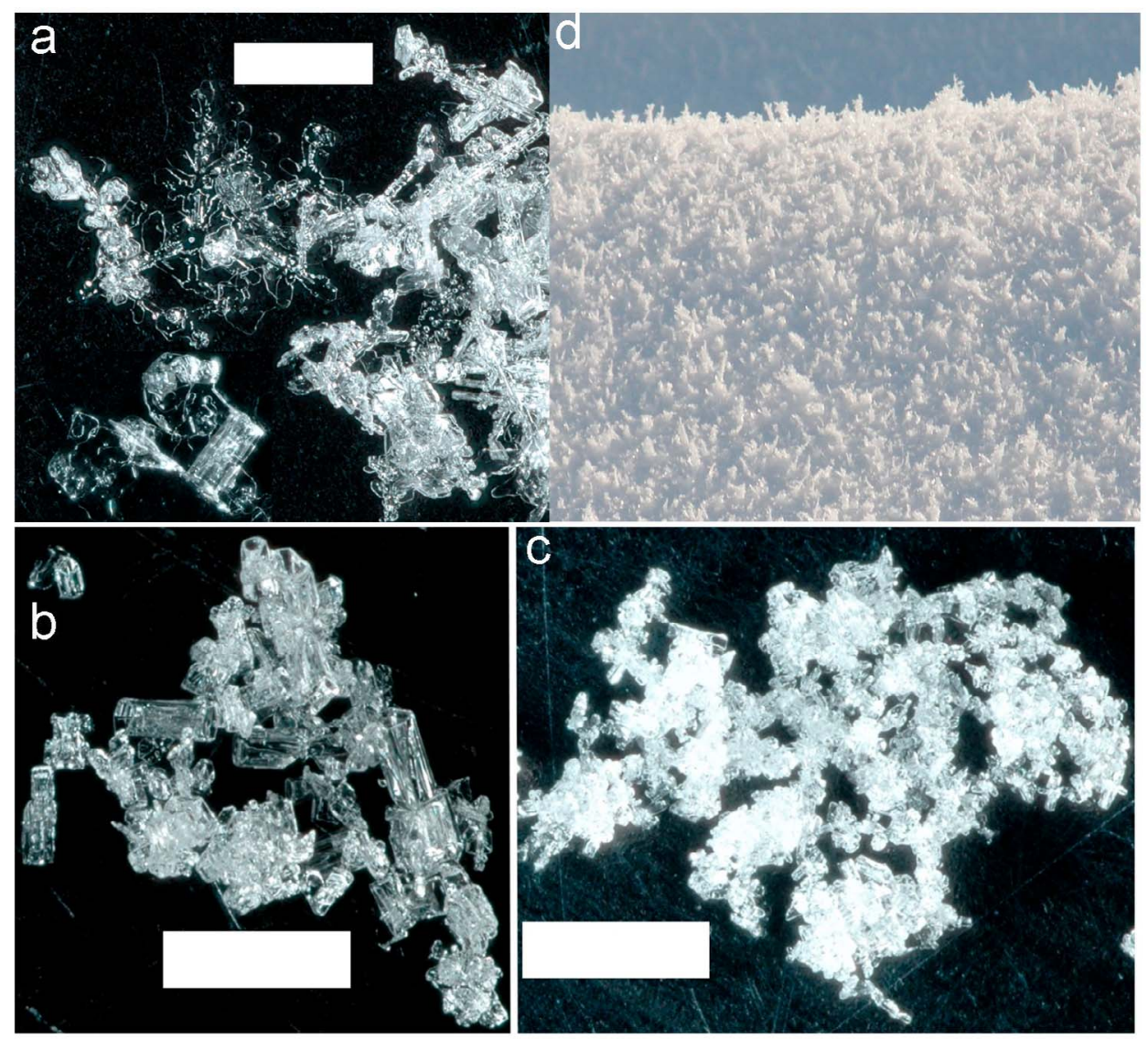

Figure 2. Photographs of snow and diamond dust crystals. Scale bars $=1 \mathrm{~mm}$. (a) Snow fall of 9 March showing a column and dendritic crystals, for the most part broken by wind; SSA $=76.7 \mathrm{~m}^{2} \mathrm{~kg}^{-1}$. (b) The 18 March DD fall, whose SSA was $97.5 \mathrm{~m}^{2} \mathrm{~kg}^{-1}$. Columns reach $600 \mu \mathrm{m}$ in length (along c axis). (c) The 15 March DD fall, SSA $=223 \mathrm{~m}^{2} \mathrm{~kg}^{-1}$. Crystals do not exceed $200 \mu \mathrm{m}$ along any c-axis. (d) Growth of feather-shaped surface hoar crystals on top of the DD. Feathers are about $2 \mathrm{~cm}$ high. Growth was more pronounced on bumps and edges of sastrugi (snow dunes) and less pronounced in hollows.

absorption spectra at each nm over the wavelength range of interest (e.g., between 300 and $450 \mathrm{~nm}$ to focus on photochemically active chromophores) to determine values of $\Sigma \alpha_{\lambda}$ (residual), i.e., the summed residual absorption.

\subsubsection{Analysis of $\mathrm{H}_{2} \mathrm{O}_{2}$}

[25] We analyzed one aliquot from each snow sample for $\mathrm{H}_{2} \mathrm{O}_{2}$ using HPLC separation (Inertsil® ODS-2 analytical column with guard column) with post-column derivatization with p-hydroxyphenylacetic acid in an enzymatic reaction to form a fluorescent dimer [Kok et al., 1995], and detection by a Shimadzu RF-551 spectrofluorometric detector. The resulting $3 \sigma$ detection limit for $\mathrm{H}_{2} \mathrm{O}_{2}$ with the HPLC method was $75 \mathrm{nM}$. More details on the $\mathrm{H}_{2} \mathrm{O}_{2}$ measurements is provided by Beine et al. [2011].

\section{Results}

\subsection{Physical Measurements}

\subsubsection{Specific Surface Area}

[26] Figure 1 shows the occurrence of precipitation and the daily accumulation of snow or DD collected in 2009. The 9-10 March event was snow. On 14 March, clouds were present but precipitating crystals were similar to those during
DD events. On 1st April, a few scattered clouds were present and a few dendritic crystals were observed, so this event is a mixed snow/DD precipitation. The SSA was measured for most observed precipitation, and is also shown in Figure 1. SSA values are for the most part in the 80 to $100 \mathrm{~m}^{2} \mathrm{~kg}^{-1}$ range, except on $15 \mathrm{March}$, where the value reached $223 \mathrm{~m}^{2} \mathrm{~kg}^{-1}$. This value is the highest SSA value ever directly measured for precipitating ice crystals. The density of the snow event on 9 March was $92 \mathrm{~kg} \mathrm{~m}^{-3}$. Clouds were then present, and crystals were dendritic or capped columns (Figure 2a). The density of DD ranged from 130 (17 March) to 231 (1st April) $\mathrm{kg} \mathrm{m}^{-3}$. DD crystals were for the most part hollow columns, with some bullets and bullet combinations (Figures $2 \mathrm{~b}$ and 2c). A few irregular crystals were present, but no plates were positively identified. Figure $2 \mathrm{~b}$ (18 March fall) is well representative of most DD falls, with most columns 100 to $600 \mu \mathrm{m}$ in the largest dimension (c axis). Figure 2c shows 15 March DD crystals, and is unusual for the campaign, in that columns are at the most $200 \mu \mathrm{m}$ along the c axis. This small crystal size explains the high SSA value.

[27] After precipitation, the SSA of DD on the surface decreased over time because of metamorphism [Cabanes 

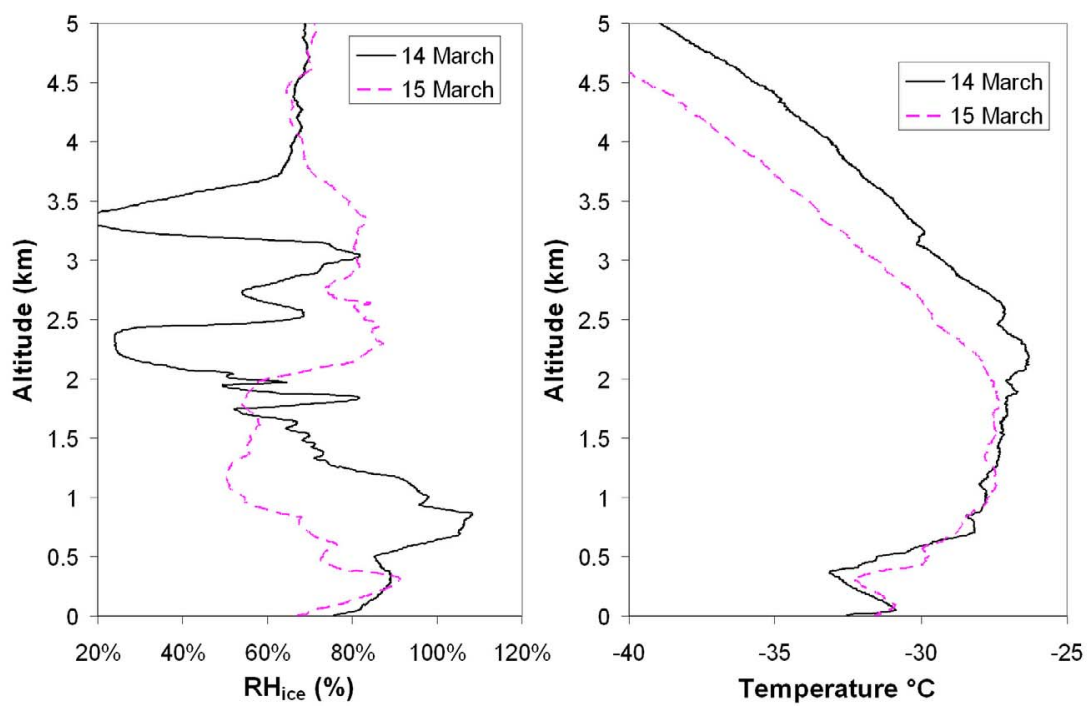

Figure 3. Vertical profiles of relative humidity (relative to ice, $\mathrm{RH}_{\text {ice}}$ ) and temperature on 14 and 15 March, when DD precipitation was observed. Data from the NOAA observatory at Barrow.

et al., 2003] and because of the growth of large feathershaped surface hoar $(\mathrm{SH})$ crystals (Figure $2 \mathrm{~d}$ ), that have a lower SSA than DD [Cabanes et al., 2002]. Because DD on the surface was a mixture of precipitation events, we were not able to monitor the SSA decrease of all the DD events. We nevertheless measured that the SSA of the 18 March precipitation decreased from 97.5 to $90.5 \mathrm{~m}^{2} \mathrm{~kg}^{-1}$ in $24 \mathrm{~h}$. On 25 March, the SSA of the DD and SH accumulated on top of the melt-freeze crust since 14 March layers was $65 \mathrm{~m}^{2} \mathrm{~kg}^{-1}$. On 4 April, DD accumulated since $1 \mathrm{st}$ April (after the last wind storm) had an SSA of $65.4 \mathrm{~m}^{2} \mathrm{~kg}^{-1}$.

\subsubsection{Conditions of Formation}

[28] It is not easy to evaluate where DD crystals formed in the atmosphere. Radiosondes were launched almost daily at noon local time from the nearby NOAA observatory. Figure 3 shows vertical profiles of temperature and relative humidity relative to ice $\left(\mathrm{RH}_{\text {ice }}\right)$ for 14 and 15 March. A $2 \mathrm{~km}$ thick inversion layer with a complex structure was present. As usual, RH values are not very accurate at these low temperatures [Walden et al., 2003]. On 15 March, it is possible that the DD formed near $330 \mathrm{~m}$, where temperature $(\mathrm{T})$ is at a minimum $\left(-32^{\circ} \mathrm{C}\right)$. There is also a marked $\mathrm{RH}_{\text {ice }}$ maximum near $2 \mathrm{~km}$, but that is an unusually high altitude for DD formation and it also corresponds to the $\mathrm{T}$ maximum. On $14 \mathrm{March}$, there are $\mathrm{RH}_{\text {ice }}$ maxima at 340 and $870 \mathrm{~m}$, and also higher up near the $\mathrm{T}$ maximum. We cannot determine whether DD formed near 340 or near $870 \mathrm{~m}$. It is possible that it formed mostly near $870 \mathrm{~m}$ on $14 \mathrm{March}$, and that conditions changed so that formation took place near $330 \mathrm{~m}$ on 15 March. These different conditions could explain the change in DD microphysics and the SSA change from 82.6 to $223 \mathrm{~m}^{2} \mathrm{~kg}^{-1}$, but this is speculation. In general, $\mathrm{RH}_{\text {ice }}$ profiles showed multiple peaks nearing or exceeding $100 \% \mathrm{RH}_{\text {ice, }}$ and in the absence of lidar, we cannot determine which one corresponds to DD formation. The $\mathrm{RH}_{\text {ice }}$ maximum at the lowest altitude was always in the elevation range $70-450 \mathrm{~m}$, and almost always coincided with a local $\mathrm{T}$ minimum, (Figure 3). This maximum may have been fed by moisture from the open lead in sea ice that was present a few $\mathrm{km} \mathrm{W} / \mathrm{NW}$ of Barrow during most of the campaign.

[29] To obtain further insight into the height of DD formation, we used data from the Calipso satellite (http:// eosweb.larc.nasa.gov/PRODOCS/calipso/table_calipso.html), which uses a lidar to sample the vertical distribution of atmospheric scatterers. However, the Calipso subtrack is seldom close to the observation site, and the satellite was not operational during all the days of interest. We found 5 days with a minimum distance between the lidar ground track and the observation site of less than $40 \mathrm{~km}$. Four of the five attenuated backscatter profiles indicate the presence of scattering layers close to the surface, mostly over the sea (on 18, 21, 25 and 28 March). Three of these profiles are shown in Figure 4, along with a map of the location of the lidar measurements. From the backscatter profiles, the average altitude of the scattering layers is around $250 \mathrm{~m}$, with a maximum of $400 \mathrm{~m}$. These observations indicate that Diamond Dust formed in a shallow layer a few hundred meters thick above the surface.

\subsubsection{Atmospheric Surface Area (ASA)}

[30] For atmospheric chemistry and physics purposes, it is useful to evaluate the ice surface area in the atmosphere (ASA), in $\mathrm{m}^{2}$ of ice surface area per $\mathrm{m}^{3}$ of air, i.e., in $\mathrm{m}^{-1}$. Note that $1 \mathrm{~m}^{-1}$ is equal to $10^{6} \mu \mathrm{m}^{2} / \mathrm{cm}^{3}$, which are the units more commonly used to discuss aerosol surface area in the atmosphere. ASA is calculated as:

$$
A S A=\frac{S S A \rho h}{v t}
$$

where $\rho$ is the DD density measured on the ground, $h$ the DD layer thickness on the ground, $v$ the settling velocity of the DD crystals in the air and $t$ the duration of the precipitation event. SSA, $\rho$ and $h$ were measured. The duration $t$ was visually estimated with an accuracy often no better than $30 \%$ and $v$ was calculated using the equations of Mitchell [1996]. Obviously, given all the variables involved in the calculation 

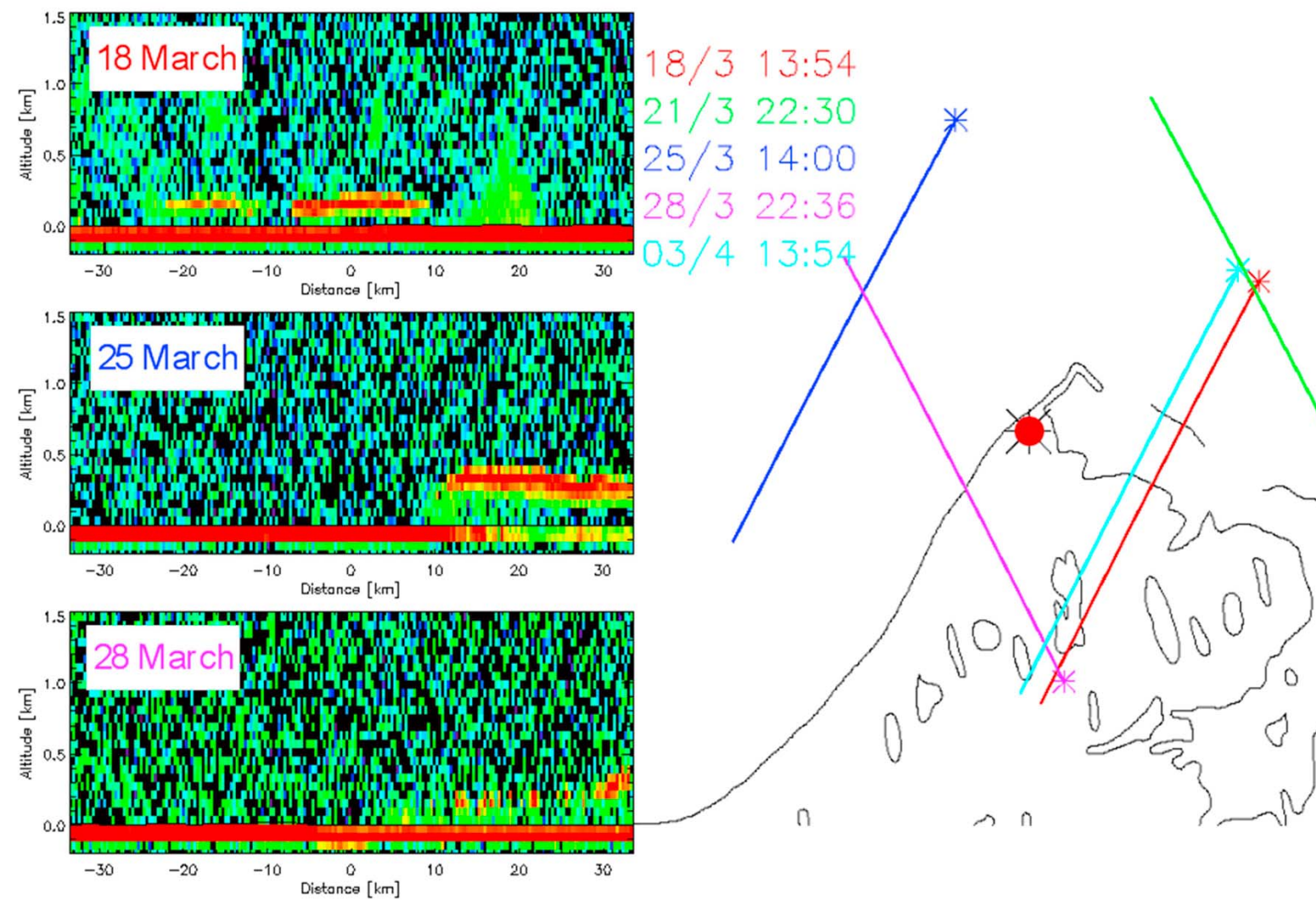

Figure 4. (right) Location of the five CALIPSO satellite subtracks that fell in the vicinity of the surface sampling site (red dot) at Point Barrow during the experiment. (left) Lidar backscatter profiles from the CALIPSO lidar for three of these days. The $x$ axis corresponds to the viewing segment as shown on the map, with the asterisks (Figure 4, right) indicating the observation start.

of the ASA and the high uncertainty on $t$, we cannot claim an accuracy better than $70 \%$.

[31] Mitchell [1996] proposed equations with adjustable coefficients for the terminal velocity of ice crystals as a function of crystal shape and size. We used the equations he derived for columns. For this crystal type, he proposed three crystal size ranges with different coefficients: $30-100 \mu \mathrm{m}$, 100-300 $\mu \mathrm{m}$, and $>300 \mu \mathrm{m}$, the size being the column greatest dimension. The relationship between SSA and column length is not simple, as for example it requires assumption on the hollowness of the columns. We therefore determined the average size of the crystals from our macrographs. The data on ASA is given in Table 1. Some days where DD was observed but its SSA not measured are not shown in Table 1. Essentially, between 14 March and 11 April, DD was observed on average at least every other day, and the atmospheric surface area of ice crystals in the atmosphere during those days was on average $2800 \mu \mathrm{m}^{2} \mathrm{~cm}^{-3}$. It even reached $11,000 \mu \mathrm{m}^{2} \mathrm{~cm}^{-3}$ on 15 March, when the highest SSA DD was observed.

\subsection{Chemical Measurements}

\subsubsection{Major Ions and Dissolved Organic Carbon}

[32] In the entire series of samples, diamond dust samples very clearly stand out as the only samples with a systematic excess in measured anions compared to the measured cations (Figure 5), which makes them acidic. They also present much lower total ion concentrations than surface snow

Table 1. Characteristics of the Diamond Dust Events Measured in Detail and Calculated Atmospheric Surface Area (ASA) of Ice Crystals $^{\mathrm{a}}$

\begin{tabular}{|c|c|c|c|c|c|c|c|c|}
\hline Date & $\mathrm{SSA}\left(\mathrm{m}^{2} \mathrm{~kg}^{-1}\right)$ & $t(\mathrm{~h})$ & Crystal Size $(\mu \mathrm{m})$ & $v(\mathrm{~m} / \mathrm{s})$ & $h(\mathrm{~mm})$ & $\rho\left(\mathrm{kg} \mathrm{m}^{-3}\right)$ & $\operatorname{ASA}\left(10^{-3} \mathrm{~m}^{-1}\right)$ & $\operatorname{ASA}\left(\mu \mathrm{m}^{2} / \mathrm{cm}^{-3}\right)$ \\
\hline 14 March & 82.6 & 3 & 250 & 0.27 & 0.6 & 130 & 2.21 & 2209 \\
\hline 15 March & 223.0 & 4 & 100 & 0.11 & 0.6 & 130 & 10.98 & 10981 \\
\hline 17 March & 90.1 & 11 & 250 & 0.27 & 0.3 & 130 & 0.33 & 329 \\
\hline $18 \mathrm{March}$ & 97.5 & 14 & 250 & 0.27 & 1 & 180 & 1.29 & 1290 \\
\hline $21 \mathrm{March}$ & 84.4 & 7 & 250 & 0.27 & 1 & 139 & 1.72 & 1724 \\
\hline 1 April am & 68.3 & 12 & 300 & 0.38 & 1 & 204 & 0.85 & 849 \\
\hline 1 April pm & 79.9 & 3 & 300 & 0.38 & 1 & 231 & 4.50 & 4497 \\
\hline 2 April & 89 & 29 & 300 & 0.38 & 0.6 & 165 & 0.22 & 222 \\
\hline
\end{tabular}

${ }^{\mathrm{a}}$ Names of variables are those of equation (1). 


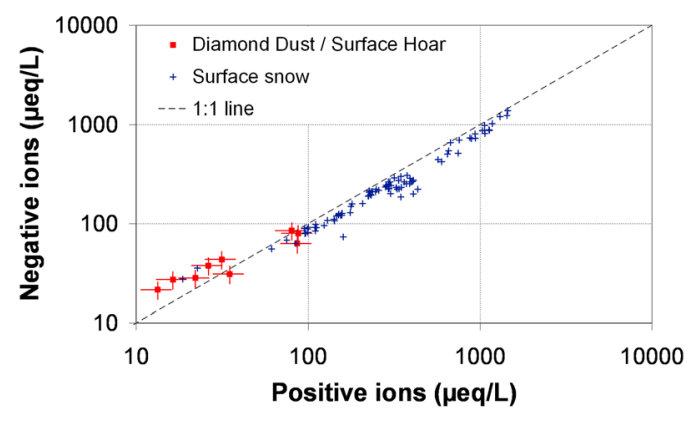

Figure 5. Ionic balance for DD (red squares) and other surface snows (blue crosses). For samples above the 1:1 line, the unmeasured cation is $\mathrm{H}^{+}$: those samples are acidic. For samples below the 1:1 line, the unmeasured anion is $\mathrm{HCO}_{3}^{-}$: those samples are alkaline. DD / SH samples are acidic, and present the lowest ion concentrations.

(Figure 5). Yet, looking at specific species, it appears that chloride, sodium, potassium, calcium and magnesium are particularly depleted in DD compared to general surface snow samples (Figure 6), whereas sulfate and nitrate concentrations are only about twice lower in DD. Bromide concentrations are comparable in all types of surface snows, and DOC is about two times higher in DD than in surface snow.

[33] This clearly indicates a very distinct chemical signature of DD, which is better viewed in so-called ratio-ration plots, popular among geochemists and recently reintroduced in the atmospheric chemistry community by Robinson et al. [2006]. Such plots are presented in Figure 7. Magnesium is used as the normative constituent because it is present in sea salt aerosol and in terrigeneous sources that are expected to heavily impact snow chemical signature. In relative terms, i.e., compared to magnesium, DD is enriched in chloride, bromide, calcium, sulfate and potassium compared to seawater and other types of continental snow. They are also enriched in DOC and to a lesser extent in nitrate compared to other types of snow. Comparison with seawater is impossible for these constituents as we do not have nitrate or DOC values for the ocean at Barrow.

\subsubsection{Aldehydes}

[34] After the most significant DD deposition events (17, 20-21 March, 1-3 April, 2009), we monitored the deposited layer at the top of the snowpack until it was remobilized by wind or covered by a new snow or DD fall. This provides information on the impact of DD deposition on snowpack chemistry. The DD layer formed on 1-3 April was sampled every $2 \mathrm{~h}$ and showed a continuous increase in FA from 3.6 ppbw on 3 April 8:45 to 7.8 ppbw on 5 April 00:00, Alaska Standard Time. A little DD fell on afternoons of 3 and 4 April, but the total amount was not significant in regard of the layer previously precipitated. The time series obtained are shown in Figure 8 where we also report our visual estimates of precipitation and remobilization events. Blowing snow collected during wind episodes is also indicated and shows concentrations in the low range of what is observed in DD. What has to be noted in Figure 8 is that aldehyde concentrations in DD almost systemically showed an increase after deposition. On 21 March, concentrations reached the highest values measured during the OASIS campaign with respective concentrations of $8.8,4.5$ and 3.3 ppbw for FA, GL and MG. Variations of concentrations in DD after deposition are reported in Table 2 for DD that fell on 17 March, 21 March and 1-3 April. This clearly indicates that significant amounts of aldehydes were either incorporated or produced in the diamond dust layer once it was deposited on the surface.

\subsubsection{Mercury}

[35] Results from the mercury concentration measurements of DD and the snowpack upper one $\mathrm{cm}$ from 2006 are given in Figure 9. Some of these data have been previously reported [Johnson et al., 2008] but we present results from additional analyses. The snow and DD mercury concentration values from duplicate samples are generally consistent. This likely suggests the samples represent homogeneous mercury loading during each sample event.

[36] The DD samples yield greater mercury concentrations than the snowpack surface on all but one of the days that both sample types were collected. There was an atmospheric mercury depletion event March 23-30 [Johnson et al., 2008] which corresponds with an increase in the surface snow mercury concentrations. Though only one DD sample was collected during the MDE, and another one at the onset of the event, they yield greater mercury concentrations than the snowpack surface samples representing the same time period. Douglas et al. [2008] reported mercury concentrations from diamond dust samples collected at our same site in Barrow in 2005, with values from 92 to $1370 \mathrm{ng} / \mathrm{L}$. They also report that DD mercury concentrations were generally 2 to 10 times greater than typical snow values; which is similar to our result.

\subsubsection{Light Absorption of Soluble Chromophores}

[37] Among all the samples that were studied during the campaign, those relevant to this work include (a) DD samples consisting exclusively or almost exclusively of fresh or recent (1 day-old) DD. Contamination by SH was minimal,

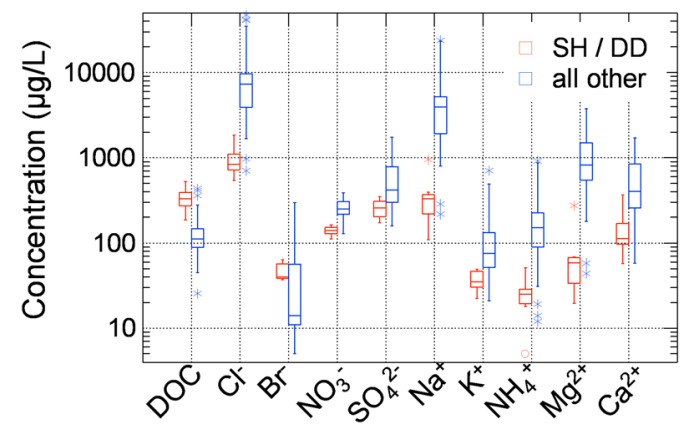

Figure 6. Box-and-whisker plots of the concentration of snow constituents in SH and DD (red boxes for each compound) compared to all other snow types (blue boxes). The center horizontal line marks the median of the sample, while the length of each box shows the central $50 \%$ of the values (i.e., the bottom and top of each box ("hinges") are the first and third quartiles). The whiskers show the range of values that fall within the inner fences (e.g., inner upper fence $=$ upper hinge $+1.5 \times$ interquartile range). Values between the inner and outer fences are plotted with asterisks (outer upper fence $=$ upper hinge $+3 \times$ interquartile range). Values outside the outer fence are plotted with circles. 

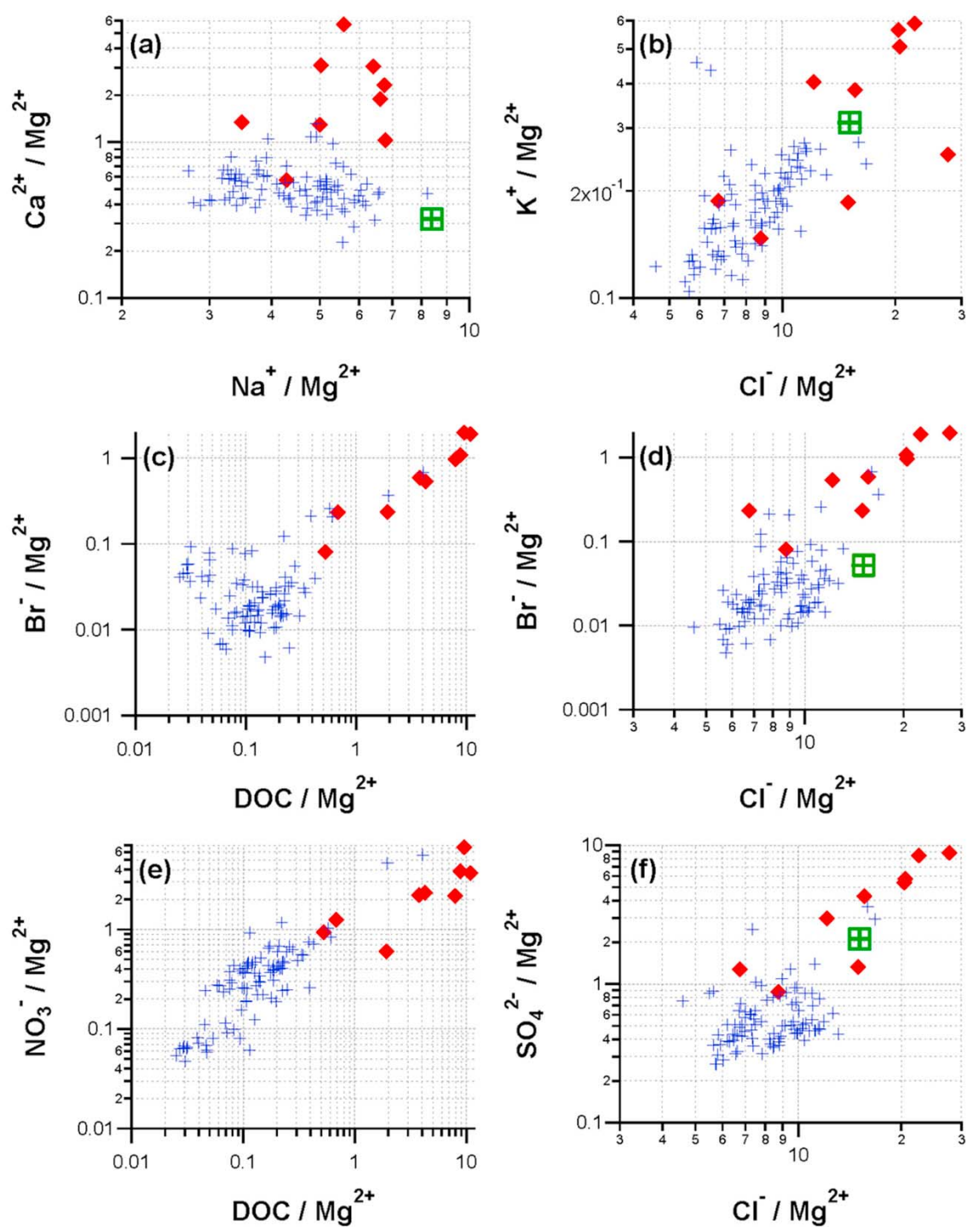

Figure 7. Ratio:ratio plots of various constituents of snow showing the very distinct signature of DD (red diamonds) compared to other surface continental snow (blue crosses) and seawater (green boxes).

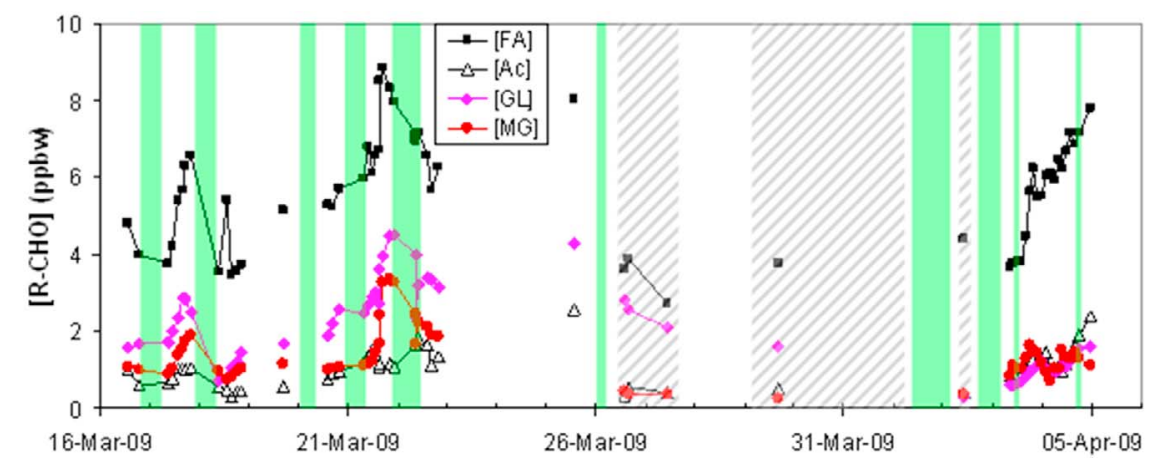

Figure 8. Times series for aldehydes measured in the DD layer at the top of the snowpack. Green areas represent our visual estimates of DD or snow precipitation, and gray striped areas represent snow remobilization by wind. 
Table 2. Variations of Aldehydes Concentrations in DD After Deposition for Three Selected Events ${ }^{\mathrm{a}}$

\begin{tabular}{lcccc}
\hline & {$[\mathrm{FA}](\mathrm{ppbw})$} & {$[\mathrm{Ac}](\mathrm{ppbw})$} & {$[\mathrm{GL}](\mathrm{ppbw})$} & {$[\mathrm{MG}](\mathrm{ppbw})$} \\
\hline 17 March & & & & \\
3/17/09 9:00 & 3.78 & 0.66 & 1.71 & 0.91 \\
3/17/09 19:45 & 6.58 & 1.05 & 2.48 & 1.91 \\
total increase & 2.80 & 0.39 & 0.77 & 1.00 \\
& & & & \\
21 March & & & & \\
3/21/09 11:45 & 6.14 & 1.51 & 2.87 & 1.25 \\
3/21/09 20:05 & 8.31 & 1.14 & 4.47 & 3.36 \\
total increase & 2.17 & -0.37 & 1.60 & 2.11 \\
& & & & \\
2-3 April & & & & \\
4/03/09 8:15 & 3.64 & 0.86 & 0.63 & 0.88 \\
4/04/09 23:20 & 7.79 & 2.37 & 1.61 & 1.10 \\
total increase & 4.14 & 1.51 & 0.98 & 0.22 \\
\hline
\end{tabular}

${ }^{a}$ Dates are given as $\mathrm{m} / \mathrm{dd} / \mathrm{yy}$.

certainly $<10 \%$ by mass. These are labeled DD-p samples (for pure); (b) aged DD samples, significantly contaminated by $\mathrm{SH}$ (possibly up to $40 \%$ by mass of $\mathrm{SH}$ ). These are labeled DD-c samples (for contaminated). (c) Samples from the top $5 \mathrm{~cm}$ of the snowpack, useful for comparison, labeled TOP samples.

[38] Figure 10 shows a depth profile of the sum of the residual absorption coefficient between 300-450 nm $\left(\Sigma \alpha_{\lambda}\right.$ (residual)). Figure 10 shows surface data from the entire campaign and the surface is thus predominantly DD-c. Values of $\Sigma \alpha_{\lambda}$ (residual) in this layer are approximately $25 \%$ higher than in the lower TOP snows. Figure 11 shows a spectral comparison of DD-p and DD-c snows. While the mean values with their standard deviation are statistically

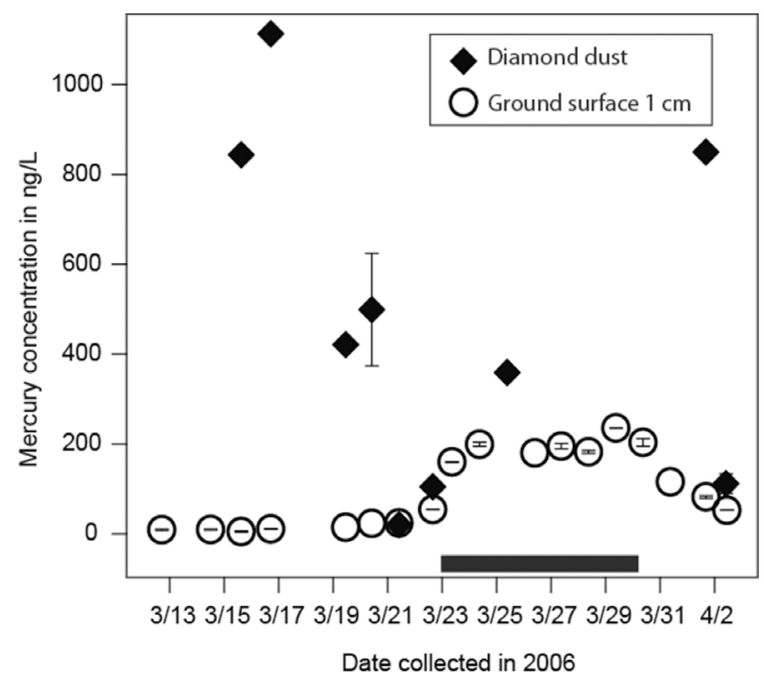

Figure 9. Mercury concentrations measured from diamond dust samples collected in glass trays and the upper one $\mathrm{cm}$ of the snowpack surface. Many samples were collected in duplicate (14 duplicates of snow and three of diamond dust) and for these samples the symbol represents the mean and the error bars represent plus and minus one standard deviation of the values. The horizontal line from March 23-30 denotes the time period when an atmospheric mercury depletion event was active based on ozone and mercury measurements [Johnson et al., 2008].

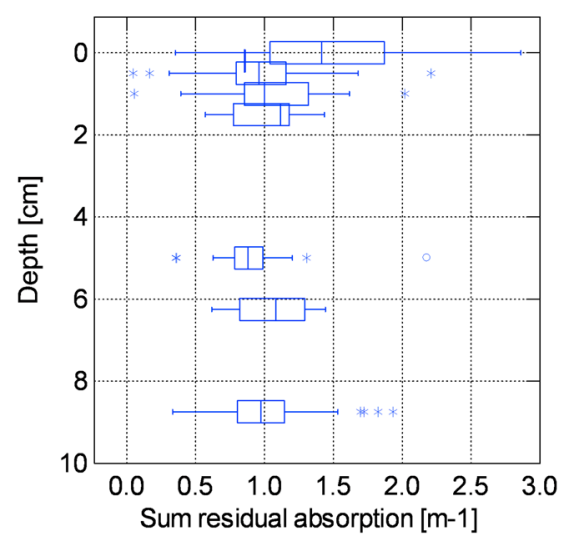

Figure 10. Depth profile of the sum of residual absorption $\Sigma \alpha_{\lambda}$ (residual)(300-450 nm) in terrestrial surface snow samples. The very surface layer (SH and DD) shows values approximately $25 \%$ higher than the wind crust immediately below.

indistinguishable, it is obvious that the DD-p show slightly higher residual absorption $\alpha_{\lambda}$ (residual) starting at about $260 \mathrm{~nm}$, and extending all through the visible spectral range. This indicates that $\alpha_{\lambda}$ (residual) decreases as DD ages and gets contaminated with increasing amounts of $\mathrm{SH}$.

[39] Figure 12 shows time series for $\Sigma \alpha_{\lambda}$ (residual) in both DD-p and DD-c for both the full measured spectral range $(220-300 \mathrm{~nm})$ and the photochemically relevant range from $300-450 \mathrm{~nm}$. If data for the period March 17 to 23 are considered, a linear regression of $-1.07 \pm 0.24 \mathrm{~m}^{-1}$ /day is statistically significant for DD-c for the range $220-300 \mathrm{~nm}$. No other statistical trend is significant. This is not surprising for DD-p; the data shown here likely arise from different precipitation events (see Figure 2), so that no relation is expected. DD-c shows a trend in the full spectrum, but not for $300-450 \mathrm{~nm}$. This indicates that the chromophores responsible for the trend absorb below $300 \mathrm{~nm}$, and not in the photochemically reactive range.

[40] Comparing the DD-c spectrum to mean surface snow at Barrow [Beine et al., 2011], an enhancement in the spectral range from 220 to $300 \mathrm{~nm}$ is seen, with a maximum around $255 \mathrm{~nm}$. This feature may help identify chemical species that might be present in DD, but not in other surface snows. In the photochemically relevant range above $300 \mathrm{~nm}$ the DD spectrum is smaller than typical Barrow surface snow, by about $20 \%$ at $320 \mathrm{~nm}$, decreasing to $50 \%$ at $450 \mathrm{~nm}$.

\subsubsection{HOOH in Barrow SH and DD Layers}

[41] At Barrow, periods of no or low winds alternated with stronger winds (R. Staebler, manuscript in preparation, 2011) that remobilized the surface snow, and thus changed the surface completely, even in the absence of fresh precipitation (Domine et al., submitted manuscript, 2011). During our campaign we observed 6 calm periods of 2 to 12 days duration. Part of the snow surfaces during these calm periods consisted of a hard thin melt-freeze crust, on which surface hoar grew and diamond dust deposited steadily (Domine et al., submitted manuscript, 2011), and where DD and SH were easy to sample separately from underlying layers.

[42] Figure 13 shows the $\mathrm{H}_{2} \mathrm{O}_{2}$ concentrations in the surface layers during one of the calm periods. $\mathrm{H}_{2} \mathrm{O}_{2}$ is 


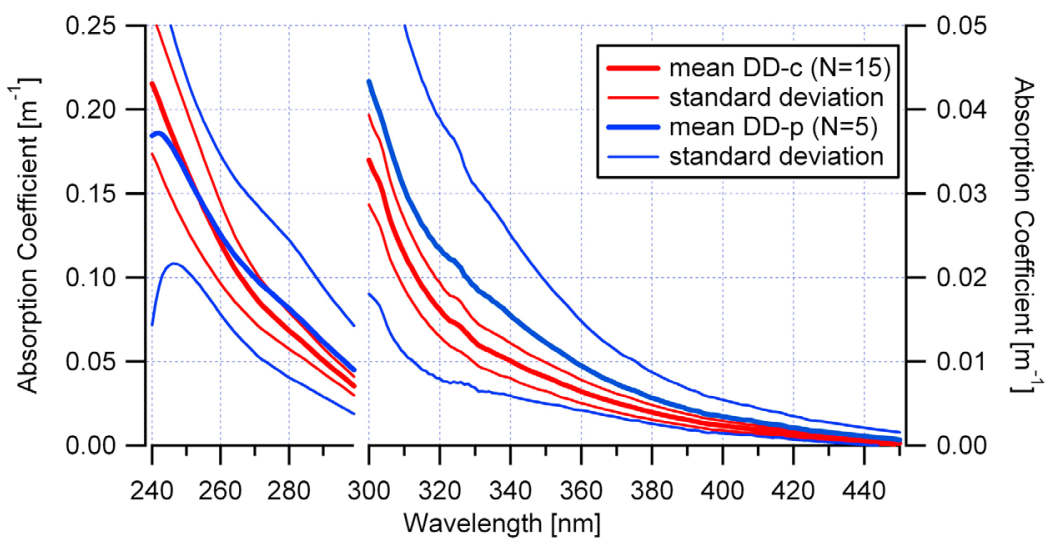

Figure 11. Mean (residual) absorption coefficient for 15 "DD-c" and 5 "DD-p" samples. Note the split $x$ axis. For the photochemically relevant range from $300-450 \mathrm{~nm}$ the right $y$ axis is valid.

significantly higher in the surface $\mathrm{DD} / \mathrm{SH}$ layer than in the deeper layers, but the $\mathrm{DD} / \mathrm{SH} \mathrm{H}_{2} \mathrm{O}_{2}$ decays, approximately with 1st order kinetics, over the course of several days. This same decay in the $\mathrm{DD} / \mathrm{SH}$ surface layer was observed during the other calm periods, with $\mathrm{H}_{2} \mathrm{O}_{2}$ lifetimes from 1.4 to 4.6 days, an average value of 3.1 days and a median value of 2.6 days. $\mathrm{H}_{2} \mathrm{O}_{2}$ in the buried layers showed no such systematic behavior.

\section{Discussion}

\subsection{Physical Aspects}

\subsubsection{Surface Area of Diamond Dust in the Atmosphere}

[43] One important result is the increase caused by DD in atmospheric surface area available for chemical reactions on surfaces,. The DD median ASA value is $1507 \mu \mathrm{m}^{2} / \mathrm{cm}^{3}$, with a maximum value of $11000 \mu \mathrm{m}^{2} / \mathrm{cm}^{3}$ on $15 \mathrm{March}$ (Table 1). In comparison, during the OASIS Campaign in Barrow, J. Smith and al. (manuscript in preparation, 2011) measured the total surface area of aerosol in the $4 \mathrm{~nm}-1 \mu \mathrm{m}$ diameter range, and found $97 \%$ of their measurements below $100 \mu \mathrm{m}^{2} / \mathrm{cm}^{3}$ (median $=41 \mu \mathrm{m}^{2} / \mathrm{cm}^{3} ; \max =500 \mu \mathrm{m}^{2} / \mathrm{cm}^{3}$ ).
[44] However, the larger size of the DD crystals, as compared to aerosol, might induce gas phase diffusion limitations, so that their potential to host surface reactions, as compared to that of aerosols, may not scale with their ASA. The first order loss constant $\mathrm{k}^{(\mathrm{I})}$ for diffusion to and reaction on particles can be written as:

$$
k^{(I)}=\gamma_{\text {eff }} \frac{\omega}{4} A S A
$$

where, $\omega=(8 \mathrm{RT} / \pi \mathrm{M})^{0.5}$ is the molecular speed, $\gamma_{\mathrm{eff}}$ is the effective heterogeneous uptake onto particles which can be expressed as a function of the reaction probability $\Gamma_{\mathrm{rxn}}$ onto the particle and $\Gamma_{\text {diff }}$ the diffusion-limited uptake coefficient for a perfectly absorbing particle [Pöschl et al., 2007]:

$$
\frac{1}{\gamma_{e f f}}=\frac{1}{\Gamma_{d i f f}}+\frac{1}{\Gamma_{r x n}}
$$

Equation (2) can then be rewritten as:

$$
k^{(I)}=\Gamma_{r x n} \frac{\omega}{4} \frac{A S A}{1+\Gamma_{r x n} / \Gamma_{\text {diff }}}=\Gamma_{r x n} \frac{\omega}{4} A S A_{\text {eff }}
$$

[45] Although unconventional, this expression allows to directly quantify the effect of gas phase diffusion, which is

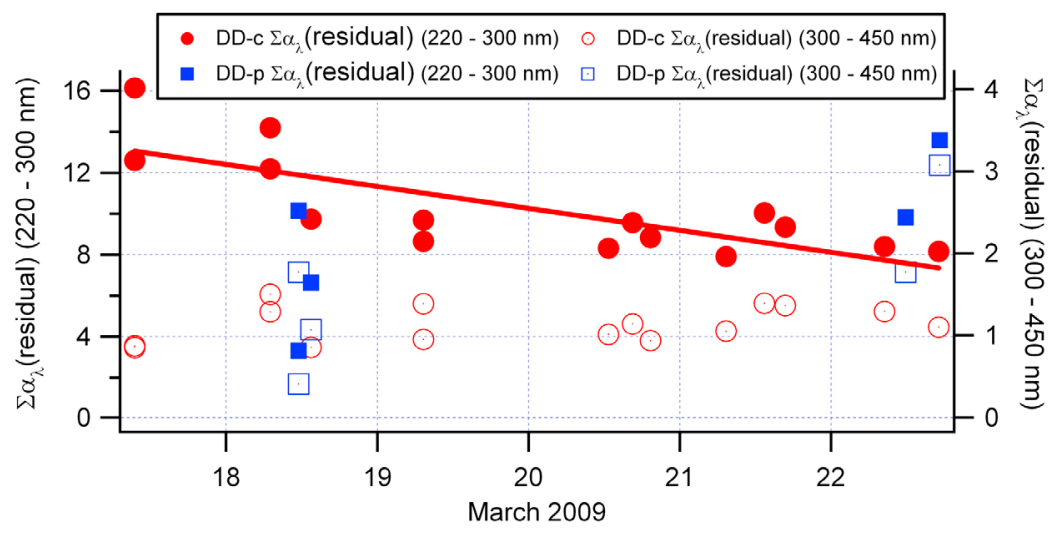

Figure 12. Time series of the sum of residual sample absorption $(220-300 \mathrm{~nm}$, right axis, filled symbols; photochemically relevant spectral range, $300-450 \mathrm{~nm}$ left axis, hollow symbols) for "DD-c" (red circles) and "DD-p" samples (blue squares). The solid red line is a linear regression of the DD-c data (left axis). 


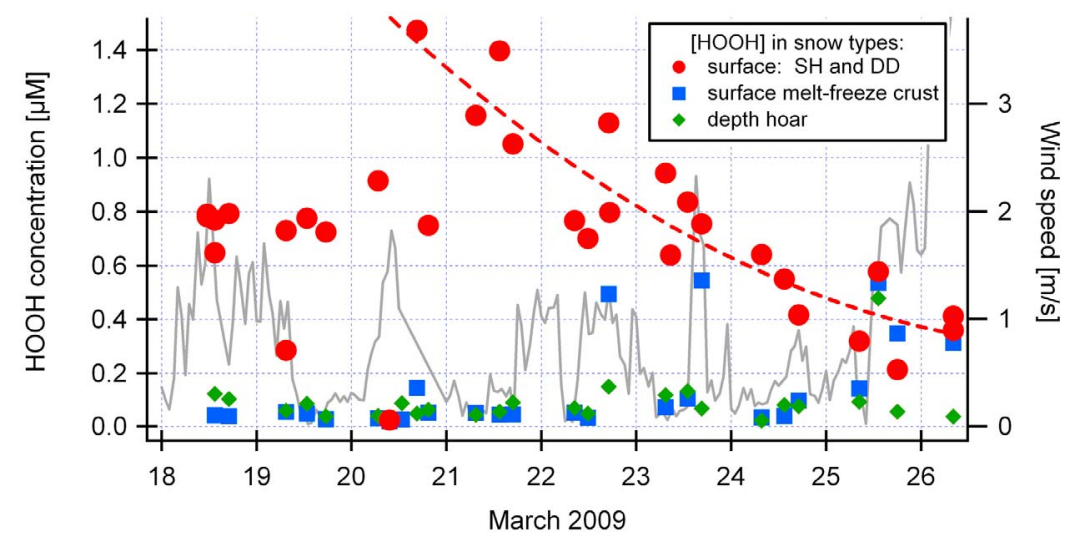

Figure 13. $\mathrm{H}_{2} \mathrm{O}_{2}$ concentrations in surface snow during one of the calm periods at Barrow, $A K$. The red dashed line shows a 1st order decay in a layer that was sampled for the first time on 20 March. The $\mathrm{H}_{2} \mathrm{O}_{2}$ lifetime in this $\mathrm{DD} / \mathrm{SH}$ layer is 4.6 days. Lower layers show significantly lower concentrations that vary little with time. The gray line shows the wind speed at $60 \mathrm{~cm}$ above the ground.

important for ice crystals because of their large size. The correction factor to apply to the DD surface concentration to get the effective surface area is $1 /\left(1+\Gamma_{\text {rxn }}\right)$. For spherical particles, [Fuchs and Sutugin, 1971] proposed an expression for $\Gamma_{\text {diff }}$ that is largely valid whatever the size of spherical particles [Pöschl et al., 2007]:

$$
\Gamma_{\text {diff }}=\frac{K n(1+K n)}{0.75+0.28 K n}
$$

where $\mathrm{Kn}$ is the Knudsen number for the reacting species, $\mathrm{Kn}=6 \mathrm{D}_{\mathrm{g}} / \omega \mathrm{d}_{\mathrm{p}}$, with $\mathrm{D}_{\mathrm{g}}$ the diffusion coefficient of the reacting species in air, and $d_{p}$ the particle's diameter.

[46] This formulation is valid for spherical particles, which DD are not, as seen in Figure 3. To avoid debating as to which crystal dimension should be used to represent its size, we calculated the correction factor for 3 different sizes: 40,100 , and $250 \mu \mathrm{m}$.

[47] The correction coefficient also depends on the reacting species. As we claim below that DD could play a role in bromine chemistry, we evaluate the correction factor for $\mathrm{HOBr}$ and $\mathrm{BrONO}_{2}$ uptake by DD particles. Extrapolating the data of Aguzzi and Rossi [2002] on ice to $240 \mathrm{~K}$ gives $\Gamma_{\text {rxn }}\left(\mathrm{BrONO}_{2}\right)=0.07$. For HOBr, Huff and Abbatt [2002] measured $\Gamma_{\mathrm{rxn}}(\mathrm{HOBr})=0.01$ at 233 and $248 \mathrm{~K}$. The resulting correction coefficients are given in Table 3. For $\mathrm{HOBr}$, for which the low reaction probability means that gas phase diffusion will hardly be limiting, the presence of DD will enhance its removal from the gas phase by a factor of up to 100. For $\mathrm{BrONO}_{2}$, which reacts faster, a strong effect will be felt when small particles are present, such as on 15 March. When only low concentrations of large particles are present, such as on 2nd April, the effect of the presence of DD on $\mathrm{BrONO}_{2}$ removal will be hard to detect.

\subsubsection{Radiative Effects}

[48] DD on the surface can affect albedo, therefore affecting radiative fluxes in the atmosphere and the energy balance of the surface through an increase in upward radiation. DD in the atmosphere can also affect radiative fluxes through increased scattering. Figure 14a compares the spectral albedo of various snow surfaces calculated with the DISORT code [Stamnes et al., 1988]: (i) a standard simplified snowpack consisting of a semi-infinite windpack layer of SSA $30 \mathrm{~m}^{2} \mathrm{~kg}^{-1}$ and density $300 \mathrm{~kg} \mathrm{~m}^{-3}$; (ii) that same windpack with a $1 \mathrm{~mm}$-thick layer of DD with SSA = $90 \mathrm{~m}^{2} \mathrm{~kg}^{-1}$ and density $=130 \mathrm{~kg} \mathrm{~m}^{-3}$; (iii) the windpack with a $5 \mathrm{~mm}$ layer of DD of the same characteristics. The incoming radiation was calculated using the SBDART model [Ricchiazzi et al., 1998] for a solar zenith angle (SZA) of $65^{\circ}$, with the option "winter arctic atmosphere" and with a snow surface. Figure 14a shows that there is a clear enhancement in the reflected IR albedo in the presence of $\mathrm{DD}$, and this is going to affect the energy budget of the surface. Considering incoming radiation between 0.3 and $2 \mu \mathrm{m}$, we calculate that for SZA $=65^{\circ}$, the upwelling shortwave flux will increase by 8.4 and $13.7 \mathrm{~W} \mathrm{~m}^{-2}$ when respectively 1 and $5 \mathrm{~mm}$ of DD are present on the surface. In the visible or UV, there is hardly any effect, as expected [Warren, 1982]. This is because we only illustrate the effect of changes in snow physical properties, and therefore do not take into account light absorbing impurities, which determine albedo in the visible and UV much more than does snow SSA [Warren, 1982].

[49] Figure 14b shows the radiative effect of DD in the atmosphere. In all cases the snow on the ground is case (ii) of Figure 14a: a windpack with $1 \mathrm{~mm}$ of DD of moderate SSA. This is about the situation of 14 March, evening. Figure 14b shows downwelling direct and diffuse shortwave radiation in the absence of DD in the air. We then performed calculations at a height of $50 \mathrm{~m}$ with the 15 March precipitation, i.e., with 4.06 crystals $\mathrm{cm}^{-3}$, of optical radius $14.67 \mu \mathrm{m}\left(\mathrm{SSA}=223 \mathrm{~m}^{2} \mathrm{~kg}^{-1}\right)$, assuming the DD layer was $150 \mathrm{~m}$ thick. Figure $14 \mathrm{~b}$ shows that atmospheric DD greatly reduces direct radiation, but also

Table 3. Correction Coefficient to Apply to Measured ASA to Account for Gas Phase Diffusion Limitations, in the Case of $\mathrm{HOBr}$ and $\mathrm{BrNO}_{2}$ Uptake by Ice Surfaces, for Various Particle Diameters $d_{p}$

\begin{tabular}{lccc}
\hline & $\mathrm{d}_{\mathrm{p}}=40 \mu \mathrm{m}$ & $\mathrm{d}_{\mathrm{p}}=100 \mu \mathrm{m}$ & $\mathrm{d}_{\mathrm{p}}=250 \mu \mathrm{m}$ \\
\hline $\mathrm{HOBr}$ & 0.519 & 0.301 & 0.147 \\
$\mathrm{BrONO}_{2}$ & 0.130 & 0.056 & 0.023 \\
\hline
\end{tabular}



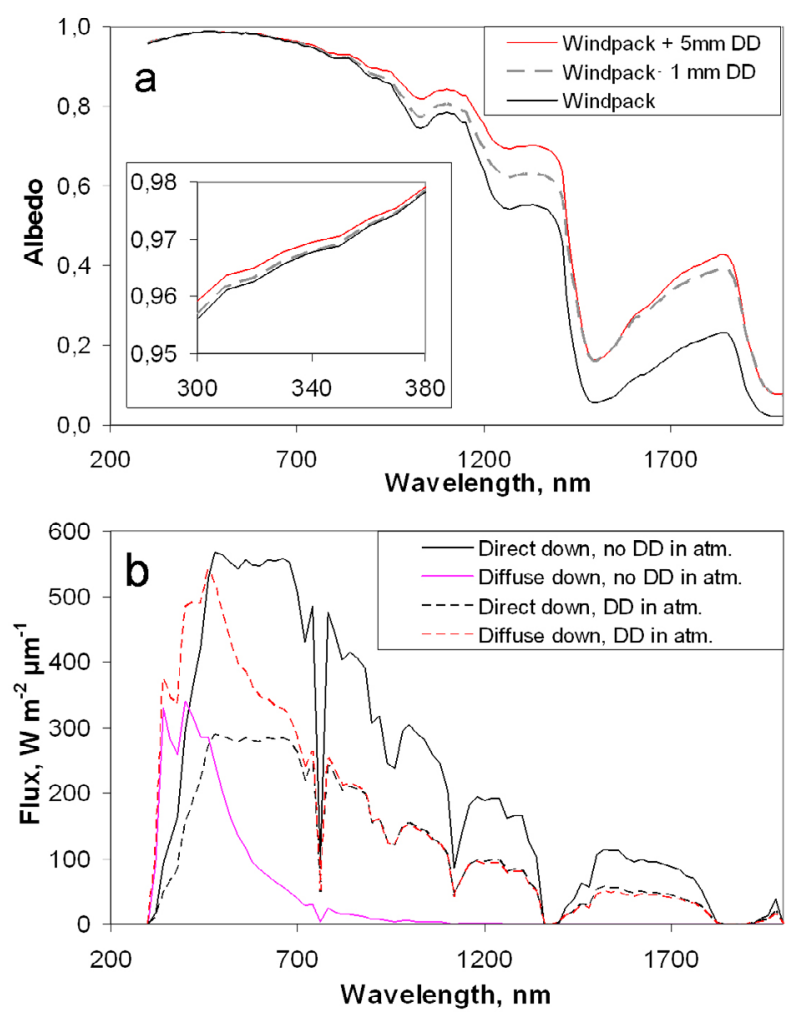

Figure 14. Radiative impact of diamond dust. (a) Impact of DD present on the surface on snow spectral albedo. The insert shows the very small effect in the UV. No DD in the atmosphere was used for these calculations. (b) Impact of DD in the atmosphere on the actinic flux. Data based on the event of 15 March 2009 were used. Ice crystals had an optical diameter of $14.67 \mu \mathrm{m}$ and a concentration of 4.06 crystals $\mathrm{cm}^{-3}$. A $150 \mathrm{~m}$-thick DD layer is used.

greatly enhances downwelling diffuse radiation. However, the total downwelling flux is hardly affected, with the decrease less than $0.5 \%$ for wavelengths shorter than 500 $\mathrm{nm}$. Likewise, the albedo is little affected, with the decrease less than $0.5 \%$ below $500 \mathrm{~nm}$. There is, however, an increase in albedo at wavelengths where ice is highly absorbing $(+19 \%$ at $1500 \mathrm{~nm})$. The increase in diffuse radiation was not visually perceptible, because ice crystals mostly forward scatter, so that extinct photons are labeled "diffuse" by radiative transfer codes while their direction is hardly affected. We conclude that DD on the surface will affect the energy balance of the surface, but that DD in the atmosphere will not affect the amount of downwelling and upwelling UV and visible radiation. DD will therefore not affect the rate of gas phase photochemical reactions. It may, however, impact atmospheric chemistry by providing surfaces and chemicals to the atmosphere.

\subsection{Chemical Aspects}

[50] The general features of Figures 5 to 7 illustrate that DD ionic and organic composition is due to processes other than those governing the composition of aged snow. This of course was expected, because as observed in other cases [e.g., Domine et al., 2004] the composition of precipitating or recent snow reflects processes during its growth in the atmosphere, while aged snow composition is mostly affected by deposition of impurities by wind pumping through snow. However, a careful examination of compositional differences can yield clues regarding the mechanism of formation of DD. At Barrow, like at other coastal sites, wind-deposited species are mostly sea salt aerosol and terrigeneous material, which considerably increase ionic concentrations and render the snow alkaline [Domine et al., 2004]. Figure 7a illustrates this point well. The aged snow population can be described mainly by a mixture between a source with a high $\mathrm{Na} / \mathrm{Mg}$ ratio (sea salt), and another source with a low $\mathrm{Na} / \mathrm{Mg}$ ratio (terrigeneous dust) (Jacobi et al., manuscript in preparation, 2011). DD composition is clearly distinct from this and indicates other sources, which can come from the ice nuclei, gaseous species incorporated during growth [Dominé and Thibert, 1996] and aerosols scavenged during growth or precipitation. These species will reflect atmospheric composition where the crystals formed, and this is expected to be different from the composition of the air near the surface, which affects aged snows. It is also noteworthy that a large fraction of the DD precipitation events took place during ODEs, i.e., during active halogen chemistry. Though this correlation is likely because both clear sky precipitation (DD) and ODEs/MDEs are more prevalent during light winds, clear skies, and cold air temperatures [Johnson et al., 2008] there is the intriguing possibility that DD precipitation events play a role in the chemical processes that drive ODEs and MDEs.

[51] The potential link between DD and halogen chemistry should be particularly visible in plots involving chloride and bromide, because $\mathrm{HCl}$ and $\mathrm{HBr}$, readily formed from $\mathrm{Cl}$ and $\mathrm{Br}$ atom chemistry through for example (R1) and (R2)

$$
\begin{aligned}
& \mathrm{Br}+\mathrm{RCHO} \rightarrow \mathrm{HBr}+\mathrm{RCO} \\
& \mathrm{Cl}+\mathrm{RCHO} \rightarrow \mathrm{HCl}+\mathrm{RCO}
\end{aligned}
$$

are readily taken up by ice. This may also explain the enrichment observed in nitrate, by hydrolysis of $\mathrm{BrONO}_{2}$ on the DD surface, as this hydrolysis reaction is thought to be the main sink for $\mathrm{NO}_{\mathrm{x}}$ during ODEs [Morin et al., 2007]. Such gas phase processes could explain the observed enrichment in DOC: active bromine and chlorine chemistry enhance the atmospheric oxidative capacity, and accelerate oxidation reactions of gaseous volatile organic compounds (VOCs) through reactive channels such as (R1) and (R2), generating more oxygenated organic compounds, likely to condense on the large surface area offered by the growing DD.

[52] These processes, however, cannot explain the observed enrichment in $\mathrm{K}$ and $\mathrm{Ca}$ (Figures $7 \mathrm{a}$ and $7 \mathrm{~b}$ ). A first tentative explanation would be to envisage some fractionation process from sea salt, for example similar to mirabilite precipitation during frost flower growth, that lead to sulfate depletion [Wagenbach et al., 1998]. Ikaite $\left(\mathrm{CaCO}_{3}, 10 \mathrm{H}_{2} \mathrm{O}\right)$ is the first salt to precipitate from brines on sea ice [Weeks and Ackley, 1982], but that would lead to Ca depletion, not enrichment. Octahydrated magnesium chloride crystalizes at $-18^{\circ} \mathrm{C}$ [Weeks and Ackley, 1982] and would lead to relative enrichment of other ions, but this temperature is rarely reached on the surface of young, thin, brine-rich sea ice. Therefore, although possible, this process does not appear like a top candidate. 

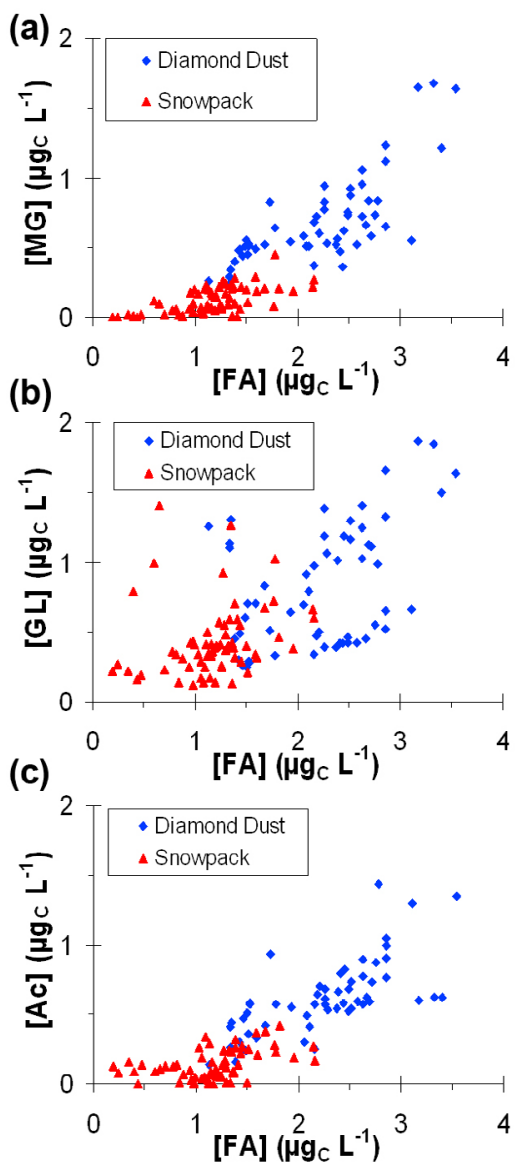

Figure 15. Correlations between FA and (a) MG, (b) GL and (c) Ac in DD samples. Data obtained for the snowpack samples are also reported for comparison purposes.

[53] Processes at the microlayer of open leads may offer an alternative explanation. Our site on the Arctic Ocean near Barrow is within $1 \mathrm{~km}$ of the coast and flaw leads typically form near this area. Based on analysis of Moderate resolution Imaging Spectroradiometer (MODIS) images of the area, there were open leads about $5 \mathrm{~km}$ north of our sampling site during most of the DD sampling period (Douglas et al., submitted manuscript, 2011). Leck and Bigg [1999] proposed that small particles could originate from bubbles bursting at the surface of open sea ice leads. These particles are enriched in organic material [Leck et al., 2002] due to the high biological activity [Matrai et al., 2008]. In leads, bubble forming processes must be different from those in the open ocean, because for example white cap waves cannot form because of insufficient wind fetch. Norris et al. [2011] observed quite intense bubbling in open leads in a summer pack ice. Although limited, their data indicate a relation between sea-to-atmosphere heat flux and bubbling intensity. They proposed that during stagnant air conditions, low turbulence lets the surface waters cool and dissolve atmospheric gases, until the cooling of surface water initiates buoyancy-driven mixing with the warmer subsurface waters. By decreasing gas solubility, this mixing would in turn initiate bubble nucleation in the subsurface. Such a process would link the observed bubbling to the sea to atmosphere heat flux, as both gas solubility in surface layer and buoyancy mixing would increase with heat flux. In the spring, such a process might even be more intense due to colder air temperatures. It would generate film drops aerosol, as recently observed by Norris et al. [2011] in summer, as long as a microlayer is present in the colder spring. This is indeed suggested by the recent finding of high bacterial counts and EPS content in brines off Barrow during the OASIS campaign [Bowman and Deming, 2010].

[54] The surface microlayer of the ocean consists partly of exopolysaccharides exuded by algae. Such organic compounds are efficient surfactants, and tend to form gel-like associations, cross-linked by divalent cations such as $\mathrm{Ca}^{2+}$ and excluding $\mathrm{NaCl}$ while retaining cell-related ions such as $\mathrm{K}^{+}$[Decho, 1990]. This type of association has recently been observed in atmospheric ultrafine aerosol [Leck and Bigg, 2010], and fits extremely well with our observed ionic enrichments in DD. It would also explain the large enrichment in carbon, and provide a clue as to why these samples have a distinct spectral signature. For such a hypothesis to prove valid, those expelled gels would need to be efficient ice forming nuclei (IFN), in order to nucleate DD crystals in the boundary layer. It has been found in the Arctic that an important fraction of IFN was carbonaceous [Rogers et al., 2001], which can be either black carbon, as proposed by Cozic et al. [2008], or organic matter. To our knowledge, there is no direct experimental evidence that biogels as mentioned by Leck and Bigg [2010] are effective IFN, although there have been ample suggestions that many biological materials, from proteinaceous material to entire cells could act as IFN [Christner et al., 2008a; Christner et al., 2008b; Prenni et al., 2009a; Prenni et al., 2009b]. Our finding suggest that these biogels may be good IFN candidates.

[55] Back-trajectories were calculated using the NOAA Hysplit model every six hours between 7 March and 5 April. Supporting the marine origin of the organics found in DD, over $85 \%$ of the trajectories were coming from the ocean, mostly from due North or NE. In particular, on 19, 25 and 28 March, when DD backscatter signal was observed, the air masses were coming from due North. Since we show that here DD forms at elevations lower than $400 \mathrm{~m}$, aerosols from marine origin were present when the DD nucleated and grew. Given the long residence time of the DD in the atmosphere (fall velocity around $0.5 \mathrm{~m} / \mathrm{s}$, often much less), DD crystals can furthermore scavenge more particles and reach the surface with organic particles on its surface, accessible to chemical reaction and photolysis.

[56] Our aldehyde data perfectly illustrate this reactivity. Aldehyde concentrations are highest in DD samples, and the amount of MG in DD is particularly striking with a mean concentration 5 times higher than in the rest of the snowpack, even though FA is always the most abundant aldehyde. If we express the aldehyde concentrations in equivalent of carbon content, we find that on average $(n=55)$, the contribution of FA to the total carbon content of aldehydes is $51 \%$, GL, MG and Ac contributing for 19, 16 and $14 \%$. Furthermore, these concentrations increased after deposition. Barret et al. [2011b] already detailed this increase for FA, and Figure 8 confirms it for Ac, GL and MGL. Figure 15 shows that the concentrations of all these species are correlated, suggesting a similar formation process. 


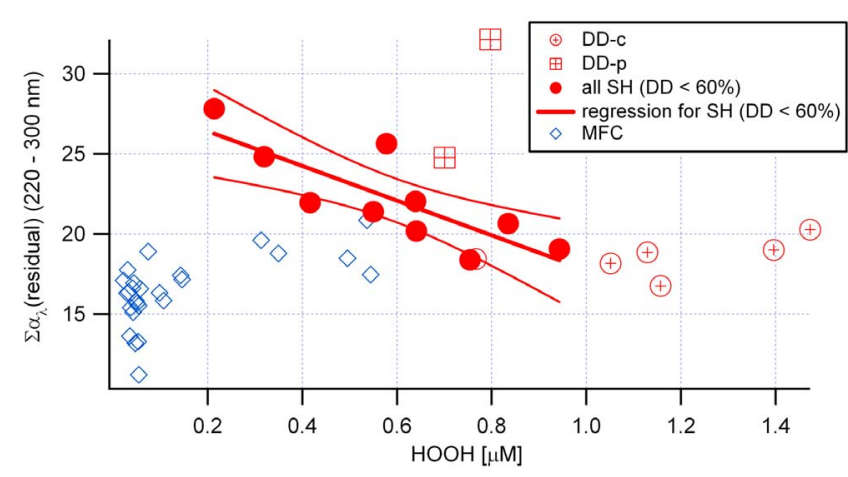

Figure 16. Relationship between $\mathrm{H}_{2} \mathrm{O}_{2}$ in the snow and $\Sigma \alpha_{\lambda}$ (residual) between $220-300 \mathrm{~nm}$. This is the spectral range where DD shows the largest difference from typical Barrow surface snow. Red symbols show surface snows, DD-c, DD-p, and SH. The thick red line shows a linear regression for $\Sigma \alpha_{\lambda}($ residual $)=28.567( \pm 3.95)-10.828$ $( \pm 6.29) \times \mathrm{HOOH}(\mathrm{p}=0.0041)$. Errors in parentheses and thin red line indicate the $95 \%$ confidence interval. For comparison, the blue diamonds show values for the melt-freeze crust (MFC) immediately below the surface snows.

[57] This last statement needs to be elaborated on. Using laboratory and field measurements, Barret et al. [2011a, $2011 \mathrm{~b}$ ] demonstrated that FA incorporates into snow crystals by forming a solid solution in ice and that equilibration with the atmosphere takes place by diffusion in ice. The incorporation mechanisms for Ac, GL and MGL in snow are not known, but given the size of the molecules, it appears unlikely that they form a solid solution with ice. Domine et al. [2010] and Houdier et al. [2002] proposed that Ac was probably present in organic aerosols. GL and MG are also known to be incorporated in particles, and are involved in the formation of secondary organic aerosols [Carlton et al., 2007; Ervens et al., 2003; Fu et al., 2008; Perri et al., 2009; Volkamer et al., 2007]. Our interpretation of the correlation between the four aldehydes studied and of their increase after precipitation, building on the idea of Barret et al. [2011b] for FA, is that they are produced by photochemistry of organic precursors [Morin et al., 2007], most likely those of marine origin mentioned above. FA, which is ice-soluble, partly incorporates into snow crystals and partly diffuses to the atmosphere, while Ac, GL and MGL are at least partly incorporated into organic aerosols, or perhaps more simply just remain in the particles where they were formed. Thus, the correlations of Figure 15 have their origin in the production mechanism and not in the incorporation mechanism. Hopefully, this photochemistry should be observable in other species and in absorption spectra.

[58] The time series of $\mathrm{H}_{2} \mathrm{O}_{2}$ in Figure 13, showing a lifetime of 4.6 days, may be another manifestation of snowpack reactivity. The photochemical lifetime for $\mathrm{H}_{2} \mathrm{O}_{2}$ on snowgrains at Barrow during the time of this campaign was on the order of 20-50 days [Beine and Anastasio, 2011], so it appears that a process other than $\mathrm{H}_{2} \mathrm{O}_{2}$ photolysis is responsible for the relatively fast loss of DD $\mathrm{H}_{2} \mathrm{O}_{2}$. Possibilities include: (a) thermal reactions of $\mathrm{H}_{2} \mathrm{O}_{2}$ with other species in the snow; (b) simple dilution by $\mathrm{SH}$; and (c) release by physical processes such as out-diffusion or during the sublimation condensation cycles of metamorphism [Perrier et al., 2002]. In terms of (a), $\mathrm{H}_{2} \mathrm{O}_{2}$ is a moderately strong oxidant that can react fairly rapidly in solution with dissolved $\mathrm{SO}_{2}$ as well as a number of organic functional groups, including alkenes, aldehydes, ketocarboxylic acids, and sulfides [Conklin et al., 1993; Hoffmann, 1977; Smith and March, 2007]. Given that the $\mathrm{DD} / \mathrm{SH}$ is enriched in organics (e.g., Figure 6), it seems likely that organic species represent a significant sink for snow grain $\mathrm{H}_{2} \mathrm{O}_{2}$, although little is known about these reactions on ice. Regarding the possibility of (b), dilution by $\mathrm{SH}$ was observed, so it does take place. However, both $\mathrm{Cl}^{-}$ and $\mathrm{NO}_{3}^{-}$concentrations in surface snow show very little variability, indicating that $\mathrm{Cl}^{-}$and $\mathrm{NO}_{3}^{-}$may have behaviors completely different from $\mathrm{H}_{2} \mathrm{O}_{2}$. Finally, out-diffusion of $\mathrm{H}_{2} \mathrm{O}_{2}$ (possibility (c)) is possible since this was observed for FA at Alert [Barret et al., 2011a; Perrier et al., 2002]. However, the comparison of the depth profiles of FA and $\mathrm{H}_{2} \mathrm{O}_{2}$ at Summit, Greenland, suggest that the diffusion of $\mathrm{H}_{2} \mathrm{O}_{2}$ is much slower than that of FA [Hutterli et al., 1999]. Sublimation/condensation during metamorphism remains a possibility, but we cannot quantify it at the moment.

[59] Figure 16 shows that the $\mathrm{H}_{2} \mathrm{O}_{2}$ decline over time in mixtures of $\mathrm{DD}$ and $\mathrm{SH}$ where $\mathrm{SH}$ dominates is associated with an increase in the residual absorption, $\Sigma \alpha_{\lambda}$ (residual), in the 220-300 $\mathrm{nm}$ spectral range. This might be due to the $\mathrm{H}_{2} \mathrm{O}_{2}$-mediated oxidation of organics (i.e., (a) above), including the conversion of aldehydes to carboxylic acids and alkenes to diols. The residual absorption steadily increases as wavelength decreases, so that may constrain which species are formed, although UV absorption spectra are difficult to use as an analytical tool. An alternate explanation for the increase in $\Sigma \alpha_{\lambda}$ (residual, 220-300 nm) is that co-condensation of $\mathrm{SH}$ and gas-phase species may selectively trap species that absorb in the far UV, so that this enhanced absorption would appear only when sufficient $\mathrm{SH}$ has grown. In conclusion to our $\mathrm{H}_{2} \mathrm{O}_{2}$ data, it is clear that we do not have the required basic data on $\mathrm{H}_{2} \mathrm{O}_{2}$-ice interactions to claim we can interpret our data in detail. What we show nevertheless supports the contention that snow is probably not just a photochemical reactor, but a medium where physical processes such as SH deposition interact with heterogeneous (photo)chemistry to change the chemical composition of snow.

[60] The evolution of absorption spectra (Figures 10-12) when the $\mathrm{SH}$ proportion is small is consistent with chemical changes. Absorption below $300 \mathrm{~nm}$ decreases over time. This may be explained by both changes in chemical concentrations and composition, in part due to photobleaching [Beine et al., 2011] and by physical processes, although clearly we lack data and understanding to quantify the contribution of each process. The emission of FA to the atmosphere [Barret et al., 2011b] and the general increase in aldehyde concentrations described here is one indication of active photochemistry in the snowpack. Aldehydes other than FA, which are probably located in organic aerosols, are most likely not hydrated on snow, or in our melted samples during absorption measurements, and therefore feature an absorption band around or above $300 \mathrm{~nm}$ [Liu et al., 2009; Malik and Joens, 2000]. Aldehydes only make up about 3\% of the mass of organics. We have clearly not analyzed all possible species and aldehydes are just an illustration and a 
partial explanation of the changes that took place. As a result of aldehyde production, other chromophores were destroyed. This may have resulted in structural changes in the complex macromolecular network that form snow organic matter, possibly contributing to the decreased absorption below $300 \mathrm{~nm}$

[61] Dilution by $\mathrm{SH}$ also had to lead to chemical changes. Surface hoar, which by definition forms at the surface of the snow by co-deposition of water vapor and impurities, grows in a medium that is chemically different from DD crystals that grow at about $300 \mathrm{~m}$ elevation in an atmosphere affected by marine emissions. Separate sampling of SH would be required to understand this dilution effect. This would be possible by placing a plastic sheet over the snow, preventing $\mathrm{SH}$ and DD from mixing. Future experiments are needed to quantify the contribution of physical and photochemical processes to the observed changes.

[62] The mercury data also indicate that snow crystals favor particular chemical processes. Even though our mercury data are from 2006 samples, conditions were similar to 2009. Back trajectories also indicate that air masses were mostly from the Arctic ocean, and MDEs and ODEs were active part of the time [Johnson et al., 2008]. That mercury concentrations are highest in DD is consistent with the suggestion that $\mathrm{Hg}^{0}$ oxidation can occur on the ice crystal surface, that $\mathrm{Hg}^{2+}$ formed in the gas phase rapidly adsorbs onto the surface of ice crystals, and/or that aerosols with sorbed $\mathrm{Hg}^{2+}$ provide a potential nucleation site around which DD crystals grow. A final possibility is that, for an unknown reason, reduction of RGM to GEM is less likely to occur when RGM is associated with DD crystals. Without a more detailed understanding of the species representing RGM, and their fundamental physical and chemical characteristics, we cannot be sure which of the aforementioned processes lead to elevated $\mathrm{Hg}$ concentrations in DD (or other vapor phase deposition such as surface hoar and frost flowers [Douglas et al., 2008]). Indeed, $\mathrm{Hg}^{0}$ depletion is believed to be caused predominantly by bromine chemistry and our Figure $7 \mathrm{c}$ shows that, in relative terms, $\mathrm{Br}^{-}$is enriched in DD. The elevated $\mathrm{Hg}$ content observed in DD may be related to the same processes that yield elevated $\mathrm{Hg}$ deposition on frost flowers and surface hoar crystals near leads with active plumes [Douglas et al., 2005, 2008].

\section{Conclusion}

[63] DD at Barrow proved to be a particular medium. Its formation and properties are probably highly linked to the frequent presence of an open lead in the sea ice off of Barrow, that provided moisture from which DD could form. We speculate that organic compounds present in the oceanic surface microlayer, and which probably include exopolysaccharides, explain the high DOC content of DD, as well as its enhanced content in $\mathrm{Ca}^{2+}$ and $\mathrm{K}^{+}$, relative to sea salt. Because of its high SSA and its high DOC content, DD favors surface reactions. These may take place on actual ice surfaces or within aerosol particles stuck to crystal surfaces or perhaps embedded within the crystals. We suggest that this may explain its high concentration in mercury and aldehydes. Once deposited, DD remains an efficient photochemical reactor, as witnessed by modifications in its absorption spectrum and chemical composition. We clearly lack data to understand the detail of the chemical reactions that take place, and we lack an exhaustive analysis of its constituents. However, a speculative suggestion is that $\mathrm{H}_{2} \mathrm{O}_{2}$ is involved in the oxidation of organics, which consumes $\mathrm{H}_{2} \mathrm{O}_{2}$ and produces organic acids and diols. Unfortunately, processes are complicated by the growth of surface hoar on top of the DD, and this physical process certainly forms ice crystals with a different signature, so that isolating processes involving only the original DD is not possible with our data. More complete chemical analysis, together with a refined understanding of physical processes at the snow surface are required to further elucidate DD chemical and physical evolution after precipitation.

[64] Acknowledgments. This work is part of the international multidisciplinary OASIS (Ocean-atmosphere-Sea Ice-Snowpack) program. It was supported by the French Polar Institute (IPEV) through grant 1017 to F.D., and by the U.S. National Science Foundation through grant NSF ATM-0807702. T.A.D. also acknowledges partial support from the U.S National Science Foundation. The Barrow Arctic Science Consortium is acknowledged for providing logistical support in the Barrow area. We thank Lee Mauldin for calculating the back trajectories. Kelsey Johnson helped with the additional mercury concentration data from the samples collected in 2006. Ghislain Picard kindly calculated the downwelling fluxes with the SBDART model.

\section{References}

Aguzzi, A., and M. J. Rossi (2002), Heterogeneous hydrolysis and reaction of $\mathrm{BrONO}_{2}$ and $\mathrm{Br}_{2} \mathrm{O}$ on pure ice and ice doped with $\mathrm{HBr}, J$. Phys. Chem. $A$, 106(24), 5891-5901, doi:10.1021/jp014383e.

Anastasio, C., and T. Robles (2007), Light absorption by soluble chemical species in Arctic and Antarctic snow, J. Geophys. Res., 112, D24304, doi:10.1029/2007JD008695.

Ariya, P. A., et al. (2004), The Arctic: A sink for mercury, Tellus, Ser. B, 56(5), 397-403, doi:10.1111/j.1600-0889.2004.00118.x.

Barret, M., S. Houdier, and F. Domine (2011a), Thermodynamics of the formaldehyde-water and formaldehyde-ice systems for atmospheric applications, J. Phys. Chem. A, 115(3), 307-317, doi:10.1021/jp108907u.

Barret, M., F. Domine, S. Houdier, J. C. Gallet, P. Weibring, J. Walega, A. Fried, and A. Richter (2011b), Formaldehyde in the Alaskan Arctic snowpack: Partitioning and physical processes involved in air-snow exchanges, J. Geophys. Res., 116, D00R03, doi:10.1029/2011JD016038.

Beine, H. J., and C. Anastasio (2011), The photolysis of flash-frozen dilute hydrogen peroxide solutions, J. Geophys. Res., 116, D14302, doi:10.1029/2010JD015531.

Beine, H. J., C. Anastasio, G. Esposito, K. Patten, E. Wilkening, F. Domine, D. Voisin, M. Barret, and S. Houdier (2011), Soluble, light-absorbing species in snow at Barrow, Alaska, J. Geophys. Res., 116, D00R05, doi:10.1029/2011JD016181.

Bottenheim, J. W., S. Netcheva, S. Morin, and S. V. Nghiem (2009), Ozone in the boundary layer air over the Arctic Ocean: Measurements during the TARA transpolar drift 2006-2008, Atmos. Chem. Phys., 9(14), 4545-4557, doi:10.5194/acp-9-4545-2009.

Bowman, J. S., and J. W. Deming (2010), Elevated bacterial abundance and exopolymers in saline frost flowers and implications for atmospheric chemistry and microbial dispersal, Geophys. Res. Lett., 37, L13501, doi:10.1029/2010GL043020.

Cabanes, A., L. Legagneux, and F. Dominé (2002), Evolution of the specific surface area and of crystal morphology of Arctic fresh snow during the ALERT 2000 campaign, Atmos. Environ., 36(15-16), 2767-2777, doi:10.1016/S1352-2310(02)00111-5

Cabanes, A., L. Legagneux, and F. Dominé (2003), Rate of evolution of the specific surface area of surface snow layers, Environ. Sci. Technol., 37(4), 661-666, doi:10.1021/es025880r.

Carlton, A. G., B. J. Turpin, K. E. Altieri, S. Seitzinger, A. Reff, H. J. Lim, and B. Ervens (2007), Atmospheric oxalic acid and SOA production from glyoxal: Results of aqueous photooxidation experiments, Atmos. Environ., 41(35), 7588-7602, doi:10.1016/j.atmosenv.2007.05.035.

Christner, B. C., C. E. Morris, C. M. Foreman, R. Cai, and D. C. Sands (2008a), Ubiquity of biological ice nucleators in snowfall, Science, 319(5867), 1214, doi:10.1126/science.1149757.

Christner, B. C., R. Cai, C. E. Morris, K. S. McCarter, C. M. Foreman, M. L. Skidmore, S. N. Montross, and D. C. Sands (2008b), Geographic, seasonal, and precipitation chemistry influence on the abundance and activity 
of biological ice nucleators in rain and snow, Proc. Natl. Acad. Sci. U. S. A., 105(48), 18,854-18,859, doi:10.1073/pnas.0809816105.

Conklin, M. H., R. A. Sommerfeld, S. K. Laird, and J. E. Villinski (1993), Sulfur-dioxide reactions on ice surfaces-Implications for dry deposition to snow, Atmos. Environ. Part A, 27(17-18), 2927-2934.

Cozic, J., S. Mertes, B. Verheggen, D. J. Cziczo, S. J. Gallavardin, S. Walter, U. Baltensperger, and E. Weingartner (2008), Black carbon enrichment in atmospheric ice particle residuals observed in lower tropospheric mixed phase clouds, J. Geophys. Res., 113, D15209, doi:10.1029/2007JD009266.

Curry, J. A., J. L. Schramm, W. B. Rossow, and D. Randall (1996), Overview of Arctic cloud and radiation characteristics, J. Clim., 9(8), 1731-1764, doi:10.1175/1520-0442(1996)009<1731:OOACAR $>2.0 . C O ; 2$

Decho, A. W. (1990), Microbial exopolymer secretions in ocean environments-Their role(s) in food webs and marine processes, Oceanogr. Mar. Biol., 28, 73-153.

Dominé, F., and P. B. Shepson (2002), Air-snow interactions and atmospheric chemistry, Science, 297(5586), 1506-1510, doi:10.1126/science. 1074610.

Dominé, F., and E. Thibert (1996), Mechanism of incorporation of trace gases in ice grown from the gas phase, Geophys. Res. Lett., 23(24), 3627-3630, doi:10.1029/96GL03290.

Dominé, F., A. Cabanes, and L. Legagneux (2002), Structure, microphysics, and surface area of the Arctic snowpack near Alert during the ALERT 2000 campaign, Atmos. Environ., 36(15-16), 2753-2765, doi:10.1016/ S1352-2310(02)00108-5.

Domine, F., R. Sparapani, A. Ianniello, and H. J. Beine (2004), The origin of sea salt in snow on Arctic sea ice and in coastal regions, Atmos. Chem. Phys., 4, 2259-2271, doi:10.5194/acp-4-2259-2004.

Domine, F., A. S. Taillandier, and W. R. Simpson (2007), A parameterization of the specific surface area of seasonal snow for field use and for models of snowpack evolution, J. Geophys. Res., 112, F02031, doi:10.1029/2006JF000512

Domine, F., S. Houdier, A. S. Taillandier, and W. R. Simpson (2010), Acetaldehyde in the Alaskan subarctic snowpack, Atmos. Chem. Phys., 10(3), 919-929, doi:10.5194/acp-10-919-2010.

Douglas, T. A., M. Sturm, W. R. Simpson, S. Brooks, S. E. Lindberg, and D. K. Perovich (2005), Elevated mercury measured in snow and frost flowers near Arctic sea ice leads, Geophys. Res. Lett., 32, L04502, doi:10.1029/2004GL022132.

Douglas, T. A., M. Sturm, W. R. Simpson, J. D. Blum, L. Alvarez-Aviles, G. J. Keeler, D. K. Perovich, A. Biswas, and K. Johnson (2008), Influence of snow and ice crystal formation and accumulation on mercury deposition to the Arctic, Environ. Sci. Technol., 42(5), 1542-1551, doi:10.1021/es070502d.

Ervens, B., P. Herckes, G. Feingold, T. Lee, J. L. Collett, and S. M. Kreidenweis (2003), On the drop-size dependence of organic acid and formaldehyde concentrations in fog, J. Atmos. Chem., 46(3), 239-269, doi:10.1023/A:1026393805907.

Foster, K. L., R. A. Plastridge, J. W. Bottenheim, P. B. Shepson, B. J. Finlayson-Pitts, and C. W. Spicer (2001), The role of $\mathrm{Br}-2$ and $\mathrm{BrC}$ in surface ozone destruction at polar sunrise, Science, 291(5503), 471-474, doi:10.1126/science.291.5503.471

Fu, T.-M., D. J. Jacob, F. Wittrock, J. P. Burrows, M. Vrekoussis, and D. K. Henze (2008), Global budgets of atmospheric glyoxal and methylglyoxal, and implications for formation of secondary organic aerosols, J. Geophys. Res., 113, D15303, doi:10.1029/2007JD009505.

Fuchs, N. A., and A. G. Sutugin (1971), Highly dispersed aerosols, in Topics in Current Aerosol Research, edited by G. M. Hidy and J. R. Brock, pp. 1-60, Pergamon, New York.

Gallet, J.-C., F. Domine, C. S. Zender, and G. Picard (2009), Measurement of the specific surface area of snow using infrared reflectance in an integrating sphere at 1310 and $1550 \mathrm{~nm}$, Cryosphere, 3(2), 167-182, doi:10.5194/tc-3-167-2009.

Girard, E., and J. P. Blanchet (2001), Simulation of arctic diamond dust, ice fog, and thin stratus using an explicit aerosol-cloud-radiation model, J. Atmos. Sci., 58(10), 1199-1221, doi:10.1175/1520-0469(2001)058<1199. SOADDI $>2.0 . \mathrm{CO} ; 2$

Grannas, A. M., et al. (2007), An overview of snow photochemistry: Evidence, mechanisms and impacts, Atmos. Chem. Phys., 7, 4329-4373, doi:10.5194/acp-7-4329-2007.

Hoffmann, M. R. (1977), Kinetics and mechanism of oxidation of hydrogen-sulfide by hydrogen-peroxide in acidic solution, Environ. Sci. Technol., 11(1), 61-66, doi:10.1021/es60124a004.

Houdier, S., S. Perrier, E. Defrancq, and M. Legrand (2000), A new fluorescent probe for sensitive detection of carbonyl compounds: Sensitivity improvement and application to environmental water samples, Anal Chim. Acta, 412(1-2), 221-233, doi:10.1016/S0003-2670(99)00875-2.
Houdier, S., S. Perrier, F. Dominé, A. Cabanes, L. Legagneux, A. M. Grannas, C. Guimbaud, P. B. Shepson, H. Boudries, and J. W. Bottenheim (2002), Acetaldehyde and acetone in the Arctic snowpack during the ALERT2000 campaign. Snowpack composition, incorporation processes and atmospheric impact, Atmos. Environ., 36(15-16), 2609-2618, doi:10.1016/S1352-2310(02)00109-7.

Houdier, S., M. Barret, F. Dominé, T. Charbouillot, L. Deguillaume, and D. Voisin (2011), Sensitive determination of glyoxal, methylglyoxal and hydroxyacetaldehyde in environmental water samples by using Dansylacetamidooxyamine derivatization and liquid chromatography/ fluorescence, Anal. Chim. Acta, 704, 162-173, doi:10.1016/j.aca.2011. 08.002 .

Huff, A. K., and J. P. D. Abbatt (2002), Kinetics and product yields in the heterogeneous reactions of $\mathrm{HOBr}$ with ice surfaces containing $\mathrm{NaBr}$ and $\mathrm{NaCl}, J$. Phys. Chem. A, 106(21), 5279-5287, doi:10.1021/jp014296m.

Hutterli, M. A., R. Rothlisberger, and R. C. Bales (1999), Atmosphereto-snow-to-firn transfer studies of HCHO at Summit, Greenland, Geophys. Res. Lett., 26(12), 1691-1694, doi:10.1029/1999GL900327.

Intrieri, J. M., and M. D. Shupe (2004), Characteristics and radiative effects of diamond dust over the western Arctic Ocean region, J. Clim., 17(15), 2953-2960, doi:10.1175/1520-0442(2004)017<2953:CAREOD $>$ 2.0.CO;2.

Johnson, K. P., J. D. Blum, G. J. Keeler, and T. A. Douglas (2008), Investigation of the deposition and emission of mercury in arctic snow during an atmospheric mercury depletion event, J. Geophys. Res., 113, D17304, doi:10.1029/2008JD009893.

Kok, G. L., S. E. McLaren, and T. A. Staffelbach (1995), HPLC determination of atmospheric organic hydroperoxides, J. Atmos. Oceanic Technol., 12(2), 282-289, doi:10.1175/1520-0426(1995)012<0282:HDOAOH $>2.0$. $\mathrm{CO} ; 2$

Lawson, R. P., B. A. Baker, P. Zmarzly, D. O’Connor, Q. Mo, J.-F. Gayet, and V. Shcherbakov (2006), Microphysical and optical properties of atmospheric ice crystals at South Pole Station, J. Appl. Meteorol. Climatol., 45(11), 1505-1524, doi:10.1175/JAM2421.1.

Leck, C., and E. K. Bigg (1999), Aerosol production over remote marine areas-A new route, Geophys. Res. Lett., 26(23), 3577-3580, doi:10.1029/1999GL010807.

Leck, C., and E. K. Bigg (2010), New particle formation of marine biological origin, Aerosol Sci. Technol., 44(7), 570-577, doi:10.1080/ 02786826.2010 .481222

Leck, C., M. Norman, E. K. Bigg, and R. Hillamo (2002), Chemical composition and sources of the high Arctic aerosol relevant for cloud formation, J. Geophys. Res., 107(D12), 4135, doi:10.1029/2001JD001463.

Liu, Y., I. El Haddad, M. Scarfogliero, L. Nieto-Gligorovski, B. TemimeRoussel, E. Quivet, N. Marchand, B. Picquet-Varrault, and A. Monod (2009), In-cloud processes of methacrolein under simulated conditions Part 1: Aqueous phase photooxidation, Atmos. Chem. Phys., 9(14), 5093-5105, doi:10.5194/acp-9-5093-2009

Mahesh, A., V. P. Walden, and S. G. Warren (2001), Ground-based infrared remote sensing of cloud properties over the Antarctic Plateau. Part I: Cloud-base heights, J. Appl. Meteorol., 40(7), 1265-1278, doi:10.1175/ 1520-0450(2001)040<1265:GBIRSO > 2.0.CO;2.

Malik, M., and J. A. Joens (2000), Temperature dependent near-UV molar absorptivities of glyoxal and gluteraldehyde in aqueous solution, Spectrochim. Acta Part A, 56(14), 2653-2658.

Matrai, P. A., L. Tranvik, C. Leck, and J. C. Knulst (2008), Are high Arctic surface microlayers a potential source of aerosol organic precursors?, Mar. Chem., 108(1-2),109-122, doi:10.1016/j.marchem.2007.11.001.

Meyer, F. G., J. A. Curry, C. A. Brock, and L. F. Radke (1991), Springtime visibility in the arctic, J. Appl. Meteorol., 30(3), 342-357, doi:10.1175/ 1520-0450(1991)030<0342:SVITA $>2.0 . \mathrm{CO} ; 2$

Mitchell, D. L. (1996), Use of mass- and area-dimensional power laws for determining precipitation particle terminal velocities, J. Atmos. Sci., 53(12), 1710-1723, doi:10.1175/1520-0469(1996)053<1710:UOMAAD> 2.0.CO;2

Morin, S., J. Savarino, S. Bekki, S. Gong, and J. W. Bottenheim (2007) Signature of Arctic surface ozone depletion events in the isotope anomaly (Delta O-17) of atmospheric nitrate, Atmos. Chem. Phys., 7, 1451-1469, doi:10.5194/acp-7-1451-2007.

Norris, S. J., I. M. Brooks, G. de Leeuw, A. Sirevaag, C. Leck, B. J. Brooks, C. E. Birch, and M. Tjernström (2011), Measurements of bubble size spectra within leads in the Arctic summer pack ice, Ocean Sci., 7(1), 129-139, doi:10.5194/os-7-129-2011

Ohtake, T., K. Jayaweera, and K. I. Sakurai (1982), Observation of ice crystal-formation in lower Arctic atmosphere, J. Atmos. Sci., 39(12), 2898-2904, doi:10.1175/1520-0469(1982)039<2898:OOICFI>2.0.CO;2

Perri, M. J., S. Seitzinger, and B. J. Turpin (2009), Secondary organic aerosol production from aqueous photooxidation of glycolaldehyde: 
Laboratory experiments, Atmos. Environ., 43(8), 1487-1497, doi:10.1016/ j.atmosenv.2008.11.037.

Perrier, S., S. Houdier, F. Dominé, A. Cabanes, L. Legagneux, A. L. Sumner, and P. B. Shepson (2002), Formaldehyde in Arctic snow: Incorporation into ice particles and evolution in the snowpack, Atmos. Environ., 36(15-16), 2695-2705, doi:10.1016/S1352-2310(02)00110-3.

Pomeroy, J. W., and D. M. Gray (1990), Saltation of snow, Water Resour. Res., 26(7), 1583-1594, doi:10.1029/WR026i007p01583.

Pöschl, U., Y. Rudich, and M. Ammann (2007), Kinetic model framework for aerosol and cloud surface chemistry and gas-particle interactionsPart 1: General equations, parameters, and terminology, Atmos. Chem. Phys., 7(23), 5989-6023, doi:10.5194/acp-7-5989-2007.

Prenni, A. J., P. J. Demott, D. C. Rogers, S. M. Kreidenweis, G. M. McFarquhar, G. Zhang, and M. R. Poellot (2009a), Ice nuclei characteristics from M-PACE and their relation to ice formation in clouds, Tellus, Ser. B, 61(2), 436-448, doi:10.1111/j.1600-0889.2009.00415.x.

Prenni, A. J., M. D. Petters, S. M. Kreidenweis, C. L. Heald, S. T. Martin P. Artaxo, R. M. Garland, A. G. Wollny, and U. Poschl (2009b), Relative roles of biogenic emissions and Saharan dust as ice nuclei in the Amazon basin, Nat. Geosci., 2(6), 402-405, doi:10.1038/ngeo517.

Ricchiazzi, P., S. R. Yang, C. Gautier, and D. Sowle (1998), SBDART: A research and teaching software tool for plane-parallel radiative transfer in the Earth's atmosphere, Bull. Am. Meteorol. Soc., 79(10), 2101-2114, doi:10.1175/1520-0477(1998)079<2101:SARATS $>2.0 . C O ; 2$

Robinson, A. L., R. Subramanian, N. M. Donahue, and W. F. Rogge (2006), Source apportionment of molecular markers and organic aerosol. 1. Polycyclic aromatic hydrocarbons and methodology for data visualization, Environ. Sci. Technol., 40(24), 7803-7810.

Rogers, D. C., P. J. DeMott, and S. M. Kreidenweis (2001), Airborne measurements of tropospheric ice-nucleating aerosol particles in the Arctic spring, J. Geophys. Res., 106(D14), 15,053-15,063, doi:10.1029/ 2000JD900790

Smith, M. B., and J. March (2007), March's Advanced Organic Chemistry, 6th ed., Wiley-Intersci., Hoboken, N. J.

Stamnes, K., S. C. Tsay, W. Wiscombe, and K. Jayaweera (1988), Numerically stable algorithm for discrete-ordinate-method radiative-transfer in multiple-scattering and emitting layered media, Appl. Opt., 27(12), 2502-2509, doi:10.1364/AO.27.002502.

van As, D., and M. R. van den Broeke (2006), Structure and dynamics of the summertime atmospheric boundary layer over the Antarctic Plateau:
2. Heat, moisture, and momentum budgets, J. Geophys. Res., 111, D07103, doi:10.1029/2005JD006956.

Volkamer, R., F. S. Martini, L. T. Molina, D. Salcedo, J. L. Jimenez, and M. J. Molina (2007), A missing sink for gas-phase glyoxal in Mexico City: Formation of secondary organic aerosol, Geophys. Res. Lett., 34, L19807, doi:10.1029/2007GL030752.

Wagenbach, D., F. Ducroz, R. Mulvaney, L. Keck, A. Minikin, M. Legrand, J. S. Hall, and E. W. Wolff (1998), Sea-salt aerosol in coastal Antarctic regions, J. Geophys. Res., 103(D9), 10,961-10,974, doi:10.1029/ 97JD01804.

Walden, V. P., S. G. Warren, and E. Tuttle (2003), Atmospheric ice crystals over the Antarctic Plateau in winter, J. Appl. Meteorol., 42(10), 1391-1405, doi:10.1175/1520-0450(2003)042<1391:AICOTA >2.0.CO;2.

Warren, S. G. (1982), Optical properties of snow, Rev. Geophys., 20(1), 67-89, doi:10.1029/RG020i001p00067.

Warren, S. G., and R. E. Brandt (2008), Optical constants of ice from the ultraviolet to the microwave: A revised compilation, J. Geophys. Res. 113, D14220, doi:10.1029/2007JD009744.

Weeks, W. F., and S. F. Ackley (1982), The growth, structure, and properties of sea ice, Rep. CRREL Monogr. 82-1, 130 pp, Cold Reg. Res. and Eng. Lab., Hanover, N. H.

C. Anastasio and H. J. Beine, Department of Land, Air and Water Resources, University of California, Davis, CA 95616, USA.

M. Barret, J.-C. Gallet, S. Houdier, and D. Voisin, Laboratoire de Glaciologie et Géophysique de l'Environnement, CNRS-INSU, BP 96, F-38402 Saint-Martin-d'Hères CEDEX, France.

J. D. Blum, Department of Earth and Environmental Sciences, University of Michigan, Ann Arbor, MI 48109, USA.

F.-M. Bréon, Laboratoire des Sciences du Climat et de l'Environnement, UMR CEA/CNRS/UVSQ, F-91191 Gif-sur-Yvette, France.

F. Domine, Takuvik Joint International Laboratory, Université Laval (Canada) and CNRS (France), 1045 Avenue de la Médecine, Québec, QC G1V 0A6, Canada. (florent.domine@gmail.com)

T. A. Douglas, U.S. Army Cold Regions Research and Engineering Laboratory, PO Box 35170, Bldg. 4070, Fort Wainwright, AK 99703 0170, USA. 